\title{
Post-Translational Inhibition of IP-10 Secretion in IEC by Probiotic Bacteria: Impact on Chronic Inflammation
}

\author{
Gabriele Hörmannsperger ${ }^{1}$, Thomas Clavel ${ }^{1}$, Micha Hoffmann ${ }^{1}$, Caroline Reiff ${ }^{2}$, Denise Kelly ${ }^{2}$, Gunnar \\ Loh $^{3}$, Michael Blaut ${ }^{3}$, Gabriele Hölzlwimmer ${ }^{4}$, Melanie Laschinger ${ }^{5}$, Dirk Haller ${ }^{1 *}$ \\ 1 Chair for Biofunctionality, ZIEL-Research Center for Nutrition and Food Science, Technische Universität München, Freising-Weihenstephan, Germany, 2 Rowett Institute \\ of Nutrition and Health, Aberdeen University, Aberdeen, United Kingdom, 3 Gastrointestinale Mikrobiologie, Deutsches Institut für Ernährungsforschung, Potsdam- \\ Rehbrücke, Nuthetal, Germany, 4 Helmholz-Zentrum München, Institute for Pathology, München-Neuherberg, Germany, 5 Department of Surgery, Technische Universität \\ München, Munich, Germany
}

\begin{abstract}
Background: Clinical and experimental studies suggest that the probiotic mixture VSL\#3 has protective activities in the context of inflammatory bowel disease (IBD). The aim of the study was to reveal bacterial strain-specific molecular mechanisms underlying the anti-inflammatory potential of VSL\#3 in intestinal epithelial cells (IEC).

Methodology/Principal Findings: VSL\#3 inhibited TNF-induced secretion of the T-cell chemokine interferon-inducible protein (IP-10) in Mode-K cells. Lactobacillus casei (L. casei) cell surface proteins were identified as active anti-inflammatory components of VSL\#3. Interestingly, L. casei failed to block TNF-induced IP-10 promoter activity or IP-10 gene transcription at the mRNA expression level but completely inhibited IP-10 protein secretion as well as IP-10-mediated T-cell transmigration. Kinetic studies, pulse-chase experiments and the use of a pharmacological inhibitor for the export machinery (brefeldin A) showed that $L$. casei did not impair initial IP-10 production but decreased intracellular IP-10 protein stability as a result of blocked IP-10 secretion. Although L. casei induced IP-10 ubiquitination, the inhibition of proteasomal or lysosomal degradation did not prevent the loss of intracellular IP-10. Most important for the mechanistic understanding, the inhibition of vesicular trafficking by 3-methyladenine (3-MA) inhibited IP-10 but not IL-6 expression, mimicking the inhibitory effects of $L$. casei. These findings suggest that $L$. casei impairs vesicular pathways important for the secretion of IP10 , followed by subsequent degradation of the proinflammatory chemokine. Feeding studies in TNF ${ }^{\Delta A R E}$ and IL-10 ${ }^{-/-}$mice revealed a compartimentalized protection of VSL\#3 on the development of cecal but not on ileal or colonic inflammation. Consistent with reduced tissue pathology in IL-10 $0^{-1-}$ mice, IP-10 protein expression was reduced in primary epithelial cells.

Conclusions/Significance: We demonstrate segment specific effects of probiotic intervention that correlate with reduced IP-10 protein expression in the native epithelium. Furthermore, we revealed post-translational degradation of IP-10 protein in IEC to be the molecular mechanism underlying the anti-inflammatory effect.
\end{abstract}

Citation: Hörmannsperger G, Clavel T, Hoffmann M, Reiff C, Kelly D, et al. (2009) Post-Translational Inhibition of IP-10 Secretion in IEC by Probiotic Bacteria: Impact on Chronic Inflammation. PLoS ONE 4(2): e4365. doi:10.1371/journal.pone.0004365

Editor: Baohong Zhang, East Carolina University, United States of America

Received September 8, 2008; Accepted December 17, 2008; Published February 6, 2009

Copyright: @ 2009 Hörmannsperger et al. This is an open-access article distributed under the terms of the Creative Commons Attribution License, which permits unrestricted use, distribution, and reproduction in any medium, provided the original author and source are credited.

Funding: Financial support for this study was obtained from the European Nutrigenomics Organisation, contract nr. FP6-506360 and the Bundesministerium für Bildung und Forschung, AZ0313814. The funders had no role in study design, data collection and analysis, decision to publish, or preparation of the manuscript.

Competing Interests: The authors have declared that no competing interests exist.

* E-mail: haller@wzw.tum.de

\section{Introduction}

Inflammatory bowel diseases (IBD) are spontanously relapsing, immunologically mediated disorders of the gastrointestinal tract. The incidence and prevalence of the two main idiopathic pathologies of IBD, Crohn's disease (CD) and ulcerative colitis (UC), are rising globally in parallel to the progression of the industrialisation. More that 3.5 million people suffer from IBD in the United States and Europe [1], but although extensive research was performed in this field, the initial trigger is still unknown and efficient therapies are not available yet. Genetical susceptibility of the host [2] and the intestinal microbiota both were found to play a pivotal role in the onset and perpetuation of IBD. Enhanced numbers of mucosa associated bacteria and decreased microbiota diversity are associated with these diseases [3]. In contrast to the fact, that IBD is the result of an overreaction of the intestinal immune system towards intestinal microbes, clinical studies showed that oral uptake of specific probiotic bacterial strains like VSL\#3 [4,5] or Escherichia coli Nissle 1917 [6,7] resulted in attenuation of IBD disease severity [8]. VSL\#3, a mixture of eight different lactic acid bacteria (Lactobacillus (L.) acidophilus, $L$. bulgaricus, L. casei, L. plantarum, Streptococcus thermophilus, Bifidobacterium (B.) breve, B. infantis, B. longum) was effective in the prevention and in the maintenance treatment of pouchitis and UC [9-14]. Apart from its protective effect in clinical studies, VSL\#3 was shown to reduce experimental colitis in IL-10-deficient (IL-10 ${ }^{-/-}$) mice. Treatment of $\mathrm{IL}-10^{-/-}$mice resulted in decreased histopathology, normalization of colonic function, barrier integrity and mucosal cytokine production [15]. Furthermore, VSL\#3 was shown to induce protective heat-shock-proteins in intestinal 
epithelial cells (IEC) [16] or proliferation of IL-10-dependent TGF $\beta$-bearing regulatory $\mathrm{T}$-cells in Thl-dependent murine colitis [17]. However, there is no study showing protective effects of VSL\#3 in the context of CD or experimental ileitis, suggesting disease-and intestinal segment-specific effects of VSL\#3. Extensive progress has been made in understanding probiotic effects of VSL\#3 in the context of IBD but the molecular mechanisms as well as strain-specificity remain to be elucidated.

IEC are crucial for maintaining intestinal homeostasis [18] and failure to control inflammatory processes at the epithelial cell level may critically contribute to the disease pathogenesis. The intestinal epithelium must interact with and adapt to the constant changing environment by processing the combined biological information from luminal enteric bacteria and host-derived signals [19]. IEC react on bacterial as well as immune-derived pro-inflammatory signals by secreting cytokines and chemokines like interleukin 6 (IL-6) and interferon $\gamma$-induced protein 10 (IP-10) to activate and attract Th1-immune cells and phagocytic cells to the site of infection. Cytokine and chemokine levels were shown to be strongly elevated in inflamed intestinal regions of IBD patients [20]. Experimental studies confirmed that IP-10 plays an outstanding role in uncontrolled disease development as the blockade of IP-10 by an anti-IP-10 antibody was sufficient to decrease disease severity in IL-10 $10^{-/-}$mice. This effect was shown to be due to reduced Thl cell generation in inductive sites and reduced recruitment of Thl effector cells to the colon [21]. Another experimental study revealed that anti-IP-10 therapy attenuates murine acquired immunodeficiency syndrome (MAIDS) colitis through the blockade of Th1-cell trafficking and the reduction of IEC apoptosis [22]. Although the importance of IP-10 as a pro-inflammatory mediator in IBD has been clearly demonstrated, the molecular mechanisms underlying the regulation of IP-10 expression in IEC during disease development are not well understood. Interestingly, recent studies revealed that probiotics are able to regulate chemokine expression in IEC. Although E. coli strain Nissle 1917 and VSL\#3 were shown to reduce TNF-or Salmonella dublin-induced IL-8 chemokine expression in IEC [23,24], the molecular mechanisms of target-specific inhibition of IEC activation through probiotic bacteria under conditions of chronic intestinal inflammation are not understood. The aim of our study was to analyze the molecular mechanisms of strain-specific effects of VSL\#3 on IP-10 production in activated IEC. Furthermore, the effect of VSL\#3 on TNF-induced ileitis in heterozygous $\mathrm{TNF}^{\triangle \mathrm{ARE}}$ mice and on colitis in IL-10 $0^{-1-}$ mice was investigated in the context of IP-10 expression in IEC.

\section{Materials and Methods}

\section{Cell culture}

The small intestinal epithelial cell line Mode-K [25] (passage 10-25) as well as the human embryonic kidney epithelial cell line HEK293 [26] was grown in a humidified 5\% CO2 atmosphere at $37^{\circ} \mathrm{C}$ to confluency in 6,12 or 24 well tissue culture plates (Cell Star, Greiner bio-one, Frickenhausen, Germany). TLR2 deficient HEK293 cells were bought from InvivoGen (Cat.Nr.: 293-null) and HEK293 cells expressing TLR2 were also bought from InvivoGen (Cat.Nr.: 293-mtlr2). The Mode-K cell culture media was Dulbecco's modified Eagle's medium (DMEM) containing $10 \%$ fetal calf serum (FCS), 1,0\% Glutamine and 0,8\% antibiotic antimycotic (Invitrogen, Carlsbad, USA). Glutamine was omitted for the cultivation of HEK293 cells and Blasticidin was added for the cultivation of the stably transfected HEK293 cells. Cell culture media was changed prior to stimulation.

\section{Cell culture stimulation and bacterial treatment}

Confluent Mode-K cell monolayers were stimulated with TNF (10 ng/ml) (R\&D Systems Europe), brefeldin A $(0,5 \mu \mathrm{M})$ (Calbiochem), lactacystin (22 mM) (Biomol), $\mathrm{NH}_{4} \mathrm{Cl}$ (20 mM) (Sigma), 3methyladenine $(5 \mathrm{mM})$ and/or VSL\#3 bacteria (VSL\#3 mixture or single strains, generous gift from Dr. DeSimone, L'Aquila, Italy) (moi 20) for $24 \mathrm{~h}$ if not otherwise indicated. Viability of cells after brefeldin A treatment (6h) (93\% of viable cells, data not shown) was analysed by a WST assay (Roche). VSL\#3 derived L. casei and L. plantarum 299v were grown anaerobically (Anaerogen, Oxoid) at $37^{\circ} \mathrm{C}$ in MRS Broth (Fluka, Heidelberg) containing 0,05\% Lcysteine (Roth). E. coli strain Nissle 1917 (a generous gift from Dr. Sonnenborn, Ardeypharm GmbH, Herdecke, Germany) was grown aerobically in LB-media. Bacteria were centrifuged (4500 g, $10 \mathrm{~min}$ ) and resuspended in DMEM. L. casei was heatkilled $\left(30 \mathrm{~min}, 90^{\circ} \mathrm{C}\right)$, fixed (fL.c) $\left(3\right.$ hours, $5 \%$ formaldehyde, $4^{\circ} \mathrm{C}$ ) or lysed by lysozyme (Sigma, $50 \mathrm{mg} / \mathrm{ml}$ ) in filter sterilized $10 \mathrm{mM}$ Tris buffer $(\mathrm{pH}$ 8). Fixed bacteria were washed three times with sterile PBS before IEG stimulation. For cell surface treatment, bacteria were incubated with Phospholipase A (2 mg/ml) (Fluka), Trypsin $(2 \mathrm{mg} / \mathrm{ml})$ (Roth) or Proteinase K $(50 \mu \mathrm{g} / \mathrm{ml})$ (Roth) in filter-sterilized Tris buffer ( $50 \mathrm{mM}$ Tris, $0,1 \mathrm{M} \mathrm{NaCl}, \mathrm{pH} 8,1 \mathrm{~h}$, $37^{\circ} \mathrm{C}$ ) in a shaker.

\section{Western blot}

Purified primary IEC or Mode-K cells were lysed in Laemmli buffer and $50 \mu \mathrm{g}$ of protein were subjected to electrophoresis on $10 \%$ or $15 \%$ SDS-PAGE gels. Anti IP-10 (R\&D Systems Europe, Arlington), anti-IкB, anti-phospho-RelA (Cell Signaling, Beverly, MA), anti-ubiquitine (Cell Signaling, Beverly, MA), anti-DsRed (clontech) and anti- $\beta$-actin-antibody (ICN, Costa Mesa, CA) were used to detect immunoreactive IP-10, IкB, phospho-RelA, DsRed, ubiquitine and $B$-actin, using an enhanced chemoluminescence light-detecting kit (GE, Arlington Heights, IL).

\section{ELISA}

IP-10 and IL-6 concentrations were determined in IEC supernatants using the appropriate ELISA kits (R\&D Systems Europe) according to the manufacturer's instructions.

\section{Chromatin Immunoprecipitation (ChIP)}

Mode-K cells in $75 \mathrm{~cm}^{2}$ flasks were pre-incubated with $L$. casei for $1 \mathrm{~h}$ and stimulated with TNF $(10 \mathrm{ng} / \mathrm{ml})$ for $2 \mathrm{~h}$. Cells were fixed by formaldehyde fixation $(1 \%)$ and nuclear extraction as well as chromatin immunoprecipitation were performed using a ChIPkit (Active Motif, Carlsbad, CA, USA) according to the manufacturer's instructions. Immunoprecipitation was carried out over night at $4{ }^{\circ} \mathrm{C}$ with an anti-NFkappaB p65 antibody (Cell Signaling, Beverly, MA). DNA/protein/antibody-complexes were collected with salmon sperm saturated protein $A / G$ agarose for $30 \mathrm{~min}$ and washed three times in high salt buffer followed by three more washes in no salt buffer. DNA was released from the immune complex by heating and subsequent proteinase $\mathrm{K}$ treatment. DNA was then extracted by phenol-chloroform and eluted in water. The input control for the PCR was DNA from total nuclear extract. PCR was performed with total DNA (input control, $1 \mu \mathrm{l})$ and immunoprecipitated DNA (1 $\mu \mathrm{l})$ using the following IP-10 promoter-specific primers 5'-AACAGCTCACGCTTTG, 5'-GTCGTGATTGGGTGACT. The length of the amplified product was $186 \mathrm{bp}$. PCR products $(10 \mu \mathrm{l})$ were subjected to electrophoresis on $2 \%$ agarose gels. 


\section{Transfection}

Mode-K cells (luciferase assay) or HEK293 cells (IP-10 overexpression assay) (50\% confluent, 24-well plate) were transfected using FuGENE (Roche, Mannheim, Germany) according to the manufacturer's instructions $(24 \mathrm{~h})$. A mixture of

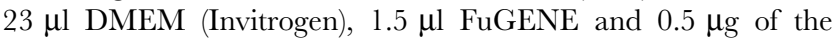
appropriate plasmid (pGL3-basic-IP10 (p-IP-10), pGL3-basic (ctrvector), pIP-10-DsRed, pDsRed-Monomer-C1 (ctr-DsRed)) was added to every well and incubated for $6 \mathrm{~h}$.

The pGL3-basic-IP10 plasmid was created by cloning a murine IP-10 promoter region (nucleotides -269 to -28 relative to the start point of transcription) into the $X h o I$ and BglII sites of the pGL3-basic vector (Promega, Madison, WI), placing the promoter directly upstream of the firefly luciferase coding sequence. Therefore, the IP-10 promoter region was amplified from Mode$\mathrm{K}$ cell genomic DNA via $p f u$ (QIAGEN, Hilden) PCR. The sense primer was 5'-GCGCTCGAGCTCAAACAGCTCAC-3' (the italic portion indicates the $X h_{0} I$ restriciton site) and the reverse primer was 5'-GCGAGATCTTCGAGTGCGGGCTG-3' (the italic portion indicates the $B g l I I$ restriction site). After digestion and ligation of PGR product and vector, the recombinant plasmid was verified by DNA sequencing (QIAGEN Sequencing Service, Hilden). The PGL3-basic-vector was used as a transfection control.

The vector pIP-10-DsRed contains a cytomegalovirus (CMV) promoter sequence driving the expression of the chemokine IP-10, which is N-terminally fused to Red Fluorescent Protein (DsRed). A $0.3 \mathrm{~kb}$ cDNA of murine IP-10, covering the whole open reading frame, was amplified from the Mode-K cell cDNA pool by $p f u$ (QIAGEN, Hilden) PCR using primers designed according to the IP-10 cDNA sequence (GenBank Accession No. NM_021274.1). The sense primer for IP-10-DsRed was 5'-GCGCTCGAGATATGAACCCAAGTGCTGCGG-3' (the italic portion indicates the $X h o I$ restriction site and bold letters indicate the start codon). The antisense primer was 5'-GCGCCCGGGAATTAAGGAGCGCTTTTAGACGT-3' (the italic portion indicates the XmaI site; stop codon in bold letters). The PGR product was digested and cloned into the XhoI and XmaI sites of pDsRed-Monomer-Cl (Clontech, Mountain View, CA). The recombinant plasmid was verified by DNA sequencing (QIAGEN Sequencing Service, Hilden). pDsRed-Monomer-C1 (constantly expressing dsRed) was used as a transfection control.

\section{Luciferase assay}

Transfected Mode-K cells were stimulated with TNF or TNF and L. casei for $24 \mathrm{~h}$. Cells were lysed in $30 \mu \mathrm{l}$ lysis buffer (Promega) and cell debris were separated by high speed centrifugation. Supernatants $(25 \mu \mathrm{l})$ were mixed with Reagent A (PJK, Kleinblittersdorf) and the firefly luminescence was measured at $550 \mathrm{~nm}$. A volume of $100 \mu \mathrm{l}$ of Reagent B (PJK, Kleinblittersdorf) was added and renilla luminescence was measured at $480 \mathrm{~nm}$. Relative luciferase activity was calculated in percentages: $\left((\text { firefly/renilla })_{\text {sample }} /(\right.$ firefly/renilla $) /$ control $) \times 100$.

\section{RNA isolation, reverse transcription and real-time PCR}

RNA from Mode-K cells or isolated primary IECs was extracted using Trizol Reagent (Invitrogen, Karlsruhe, Germany) according to the manufacturer's instructions. Extracted RNA was solved in $20 \mu \mathrm{l}$ water containing $0.1 \%$ diethyl-pyrocarbonate. RNA concentration and purity $\left(\mathrm{A}_{260} / \mathrm{A}_{280}\right.$ ratio) was determined by spectrophotometric analysis (ND-1000 spectrophotometer, NanoDrop Technologies, Willigton, USA). Reverse transcription was performed using $1 \mu \mathrm{g}$ total RNA. Real-time PCR was performed using $1 \mu \mathrm{l} \mathrm{cDNA}$ in a Light CyclerTM system (Roche Diagnostics, Mannheim, Germany) as previously described [27].
Primer sequences were: TLR2; sense 5'-TGGGGGTAACATCGCT and reverse 5'-CATCTACGGGCAGTGG, IP-10; sense 5'-TCGCTCTCGCAAGGAC and reverse 5'-TTGGGTAAACGCTTTCAT; 18S; sense 5'-CGGCTACGACATCCAAGGAA and reverse 5'-GCTGGAATTACGGCGGCT. The amplified product was detected by the presence of a SYBR green fluorescent signal. Melting curve analysis was used to document amplicon specificity and crossing points (Cp) were determined. Relative induction of gene mRNA expression was calculated according to the $2^{-\Delta \Delta \mathrm{Cp}}$ [28] method and normalized to the expression of $18 \mathrm{~S}$. Data were expressed as fold change against untreated cells or wildtype mice. Presence or absence of TLR2 transcripts in the transfected HEK293 cells was proven by running a $\%$ Agarose gel with amplicons $(321 \mathrm{bp})$ generated by reverse transcription of mRNA isolated of the HEK293 cells followed by real-time PCR.

\section{T cell transmigration assay}

Murine splenocytes were isolated from a fresh spleen (mouse genotype: C57Bl/6/N) and activated with $2,5 \mu \mathrm{g} / \mathrm{ml}$ Concavalin A (Sigma) in RPMI $(+10 \% \mathrm{FCS})$ at $37^{\circ} \mathrm{C}$ and $5 \% \mathrm{CO} 2$ for 16 hours. Cells were then centrifuged and about $1 \times 10^{8}$ cells were resuspended in $1 \mathrm{ml} \mathrm{RPMI} / 25 \mathrm{mM}$ Hepes. The cell suspension was then given onto $5 \mathrm{ml}$ NycoPrep 1,077 A (AXIS-SHIELD, Oslo via Progen) and centrifuged (600 g, $20 \mathrm{~min})$. The activated T lymphoblasts which accumulate at the interphase between media and NycoPrep were taken and resuspended in $30 \mathrm{ml}$ washing buffer (RPMI/5\%FCS/25mM Hepes). The cells were washed three times $(250 \mathrm{~g}, 10 \mathrm{~min})$ and resuspended to a final cell number of $2 \times 10^{6}$ cells $/ \mathrm{ml}$ transmigration media (RPMI $/ 5 \% \mathrm{FCS} / 25 \mathrm{mM}$ Hepes). The activated murine $\mathrm{T}$ lymphoblasts were seeded on top of transwell filters ( $5 \mu \mathrm{m}$ pore size) at a concentration of $2 \times 10^{5}$ cells $/ \mathrm{ml}$ transmigration media. The lower chamber was filled with $500 \mu \mathrm{l}$ of transmigration medium and $100 \mu \mathrm{l}$ of pure cell culture media or cell culture media from stimulation experiments with Mode-K cells (control, TNF, TNF/fL.c) or TNF-conditioned media supplemented with either a neutralizing anti-IP-10 antibody $(30 \mu \mathrm{g} / \mathrm{ml})$ (R\&D Systems) or a control goat-IgG $(30 \mu \mathrm{g} / \mathrm{ml})$ (Dianova). The assay was then incubated for 2 hours $\left(37^{\circ} \mathrm{C} / 5 \%\right.$ $\mathrm{CO}_{2}$ ) and the number of transmigrated cells in the lower chamber was analyzed using a CellCounter (Axiovision). The assay was performed in triplicates and the number of transmigrated cells at three representative regions (roi) of each single triplicate was measured.

\section{Co-immunoprecipitation}

Mode-K cells (6-well plates) were stimulated with TNF alone or TNF and L. casei for $6 \mathrm{~h}$. Cells were lysed in $200 \mu \mathrm{l}$ of $1 \times$ lysis buffer (Cell Signaling, Beverly, MA) supplemented with PMSF $(1 \mathrm{mM})$. Cell debris were removed by centrifugation $(1400 \mathrm{~g}$, $10 \mathrm{~min})$ and supernatants were incubated with anti-IP-10antibodies (R\&D Systems Europe) $\left(3 \mathrm{~h}, 4^{\circ} \mathrm{C}\right)$ in a shaker. Samples were then incubated over night at $4^{\circ} \mathrm{C}$ in a shaker together with $13 \mu \mathrm{l}$ of protein A/G beads (Santa, Cruz, Europe), which were previously washed twice with lxlysis buffer (Cell Signaling, Beverly, MA). Beads were collected by centrifugation (5 min, $8000 \mathrm{~g}$ ), washed twice with 1xlysis buffer and resuspended in $50 \mu \mathrm{l}$ Laemmli buffer for subsequent Western blot analysis.

\section{Pulse-chase experiment}

Mode-K cells (6-well plates) in DMEM (0,5\% FCS) were stimulated with TNF during the pulse period ( $\mathrm{S}^{35}$ Methionine/ Cysteine Labeling Mix, $25 \mu \mathrm{Ci} / \mathrm{ml}$ (Perkin Elmer)) (3h). After the pulse period, the cells were washed three times with $1 \times$ PBS and 
A
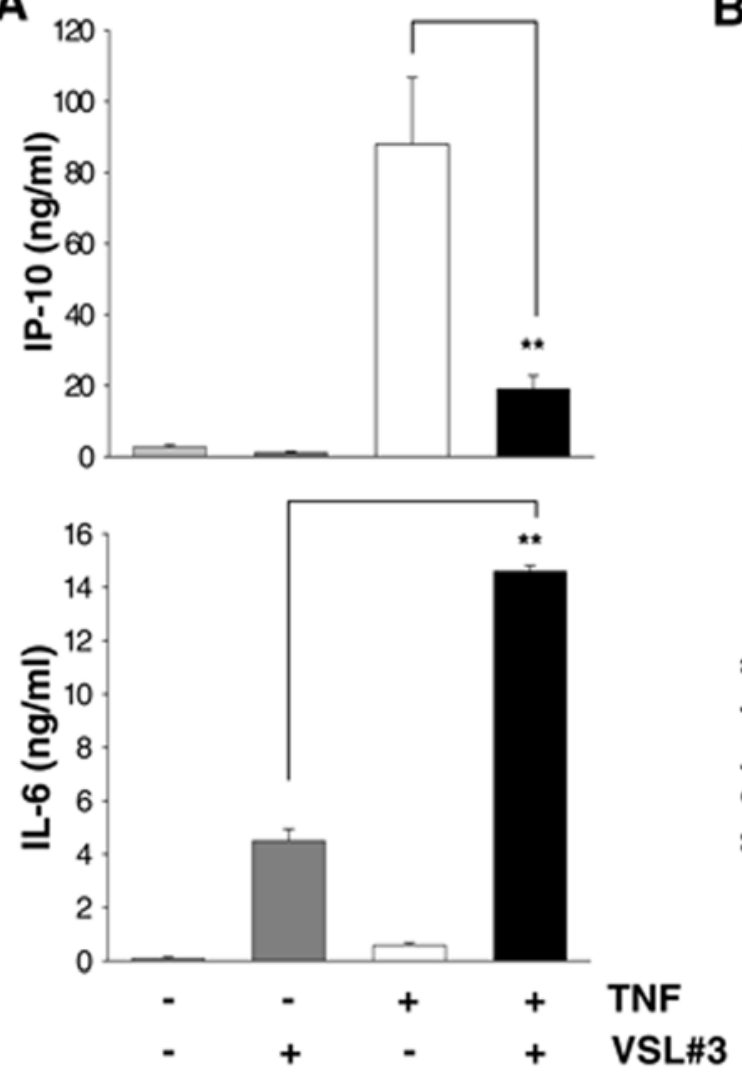

B
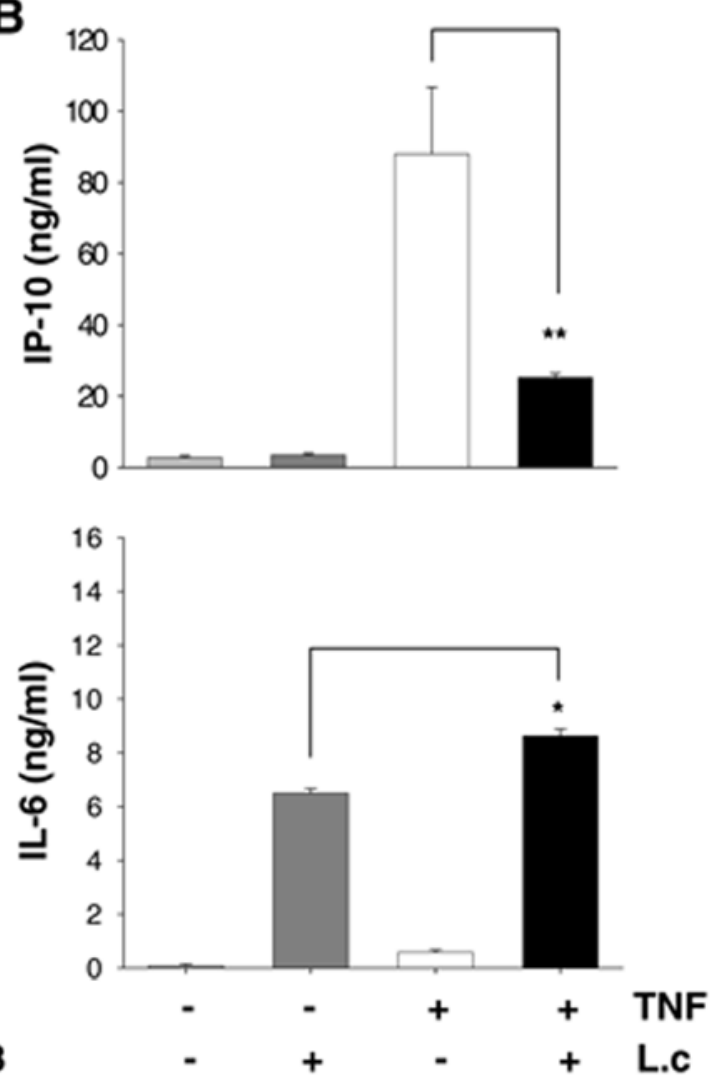

C

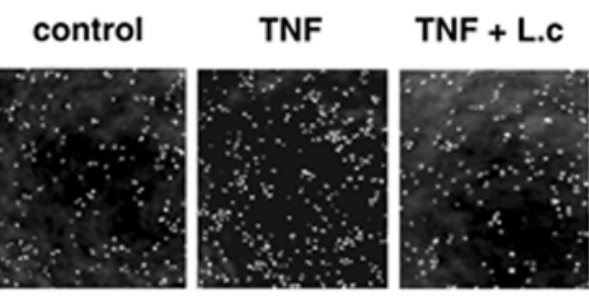

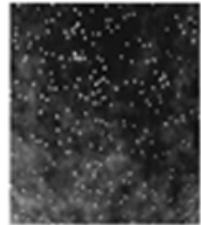

TNF+ goat IgG

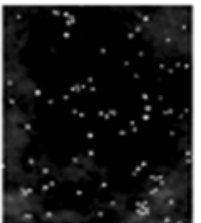

TNF+ anti-IP-10

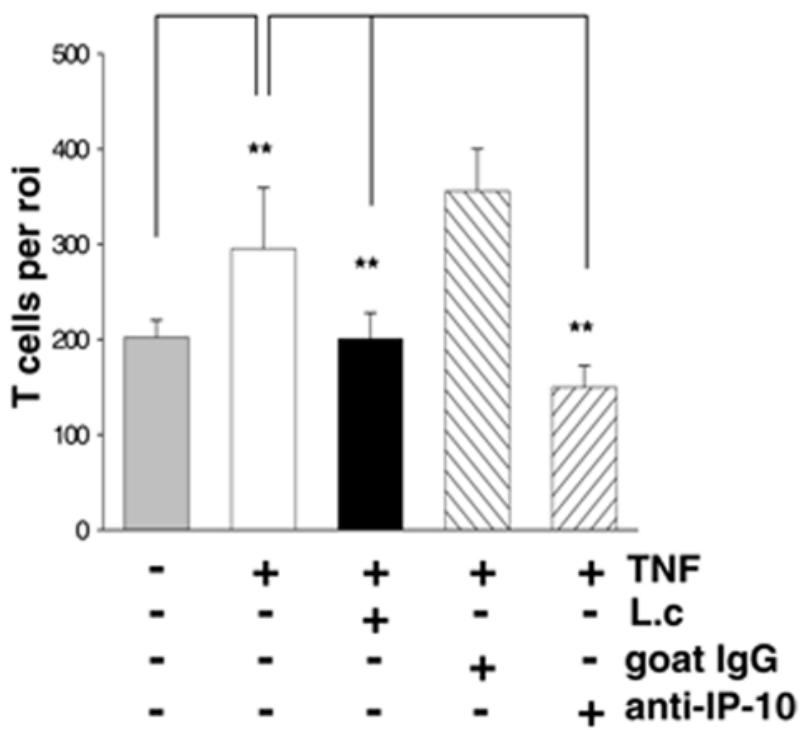

Figure 1. L. casei selectively inhibits TNF-induced secretion of chemotactically functional IP-10. Mode-K cells were stimulated for $24 \mathrm{~h}$ with (A) VSL\#3 (moi 20) or (B) L. casei (moi 20) with or without TNF $(10 \mathrm{ng} / \mathrm{ml}$ ) activation for $24 \mathrm{~h}$. The concentration of IP-10 and IL-6 in cell culture supernatants was measured by ELISA. Bars represent mean values (+/- SD) of triplicate samples. (C) $100 \mu \mathrm{I}$ DMEM or cell culture supernatant from a $24 \mathrm{~h}$ stimulation experiment with Mode-K cells (control, TNF $(10 \mathrm{ng} / \mathrm{ml})$, TNF + L. casei (moi 20)) were added to $500 \mu \mathrm{l}$ of transmigration medium. The amount of transmigrated cells per region of interest was determined by axiovision cell counting. Pictures show representative sections of transmigrated cells of three independent experiments and bars represent mean values (+/-SD) of triplicate samples.

doi:10.1371/journal.pone.0004365.g001 

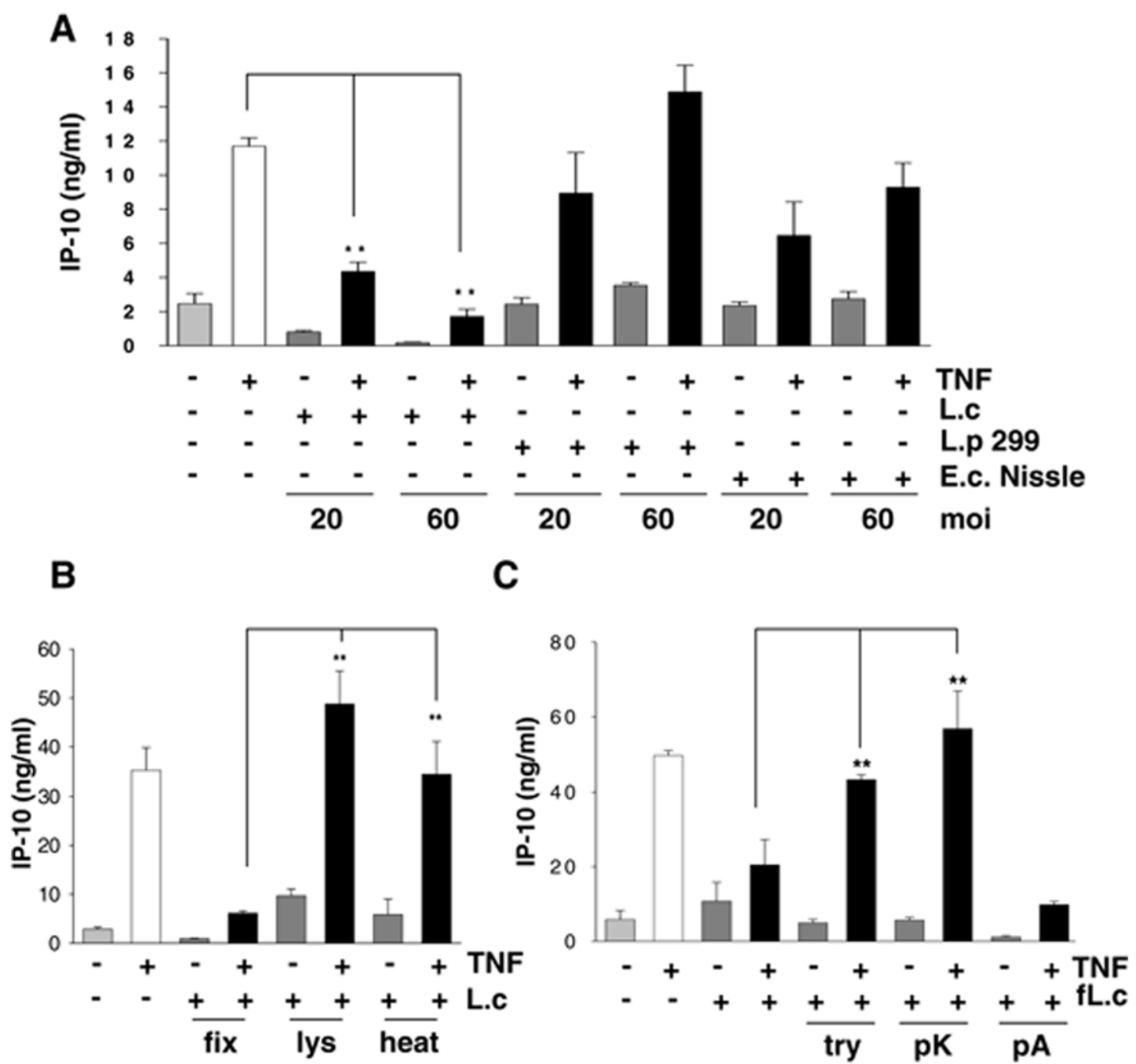

D

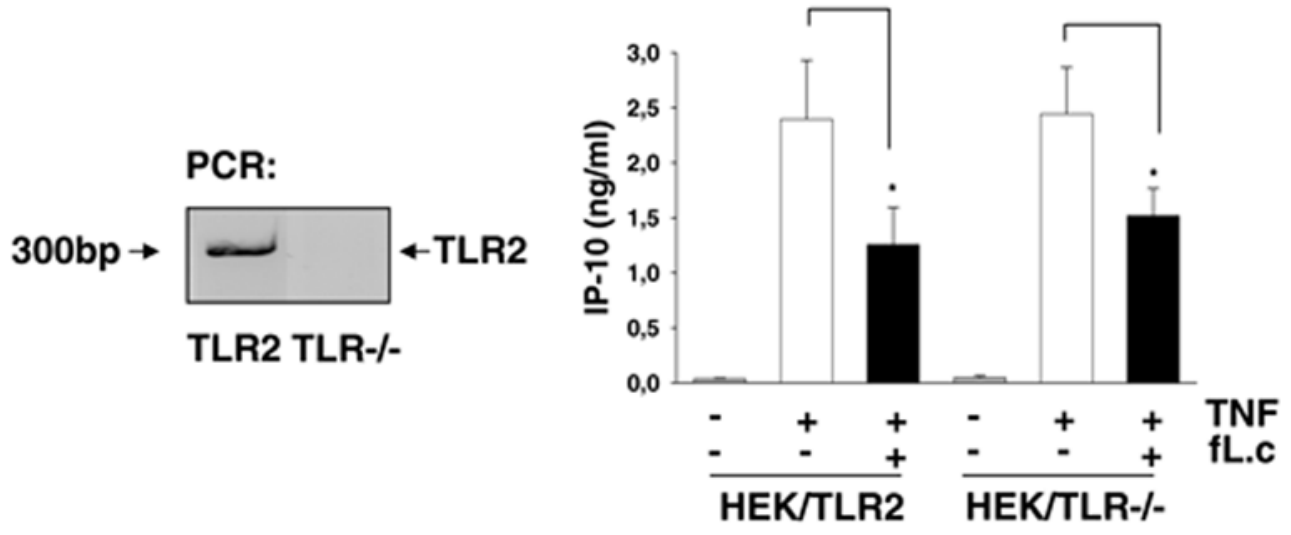

Figure 2. The inhibition of TNF-induced IP-10 secretion is mediated by a surface protein of $L$. casei. (A) Mode-K cells were stimulated for $24 \mathrm{~h}$ with L. casei, Lactobacillus plantarum 299v or E. coli Nissle 1917 (moi as indicated) with or without TNF (10 ng/ml) activation for $24 \mathrm{~h}$. The concentration of IP-10 and IL-6 in cell culture supernatants was measured by ELISA. Bars represent mean values (+/- SD) of triplicate samples. (B) Mode-K cells were stimulated with L. casei (moi 20) killed by formaldehyde fixation (fix), lysozyme (lys)-digestion or heat (heat)-treatment with or without TNF (10 ng/ml) activation for $24 \mathrm{~h}$. (C) L. casei was treated with trypsin (try), proteinase K (pK) or phospholipase A (pA) followed by formaldehyde-fixation (fL.c). (D) TLR2 deficient as well as TLR2 expressing HEK293 cells (absence/presence of TLR2 in the cells was analysed by realtime PCR) were stimulated for $24 \mathrm{~h}$ with TNF $(10 \mathrm{ng} / \mathrm{ml}$ ) and L. casei (moi 20). IP-10 concentration was measured in the culture supernatants by ELISA. The bars represent mean values $(+/-\mathrm{SD})$ of triplicate samples. doi:10.1371/journal.pone.0004365.g002 
B
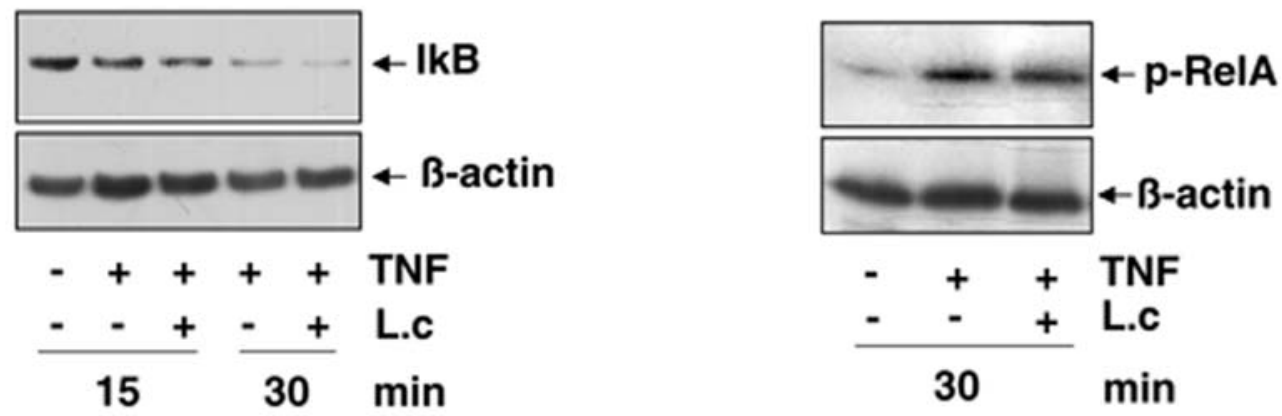

C

ChIP: IP-10 promoter

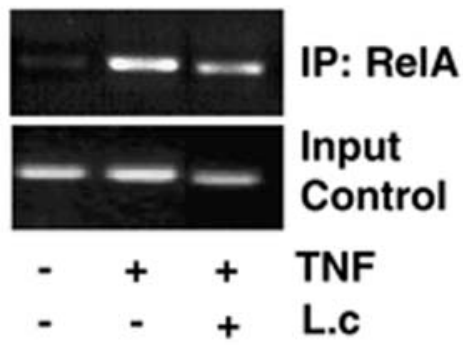

E
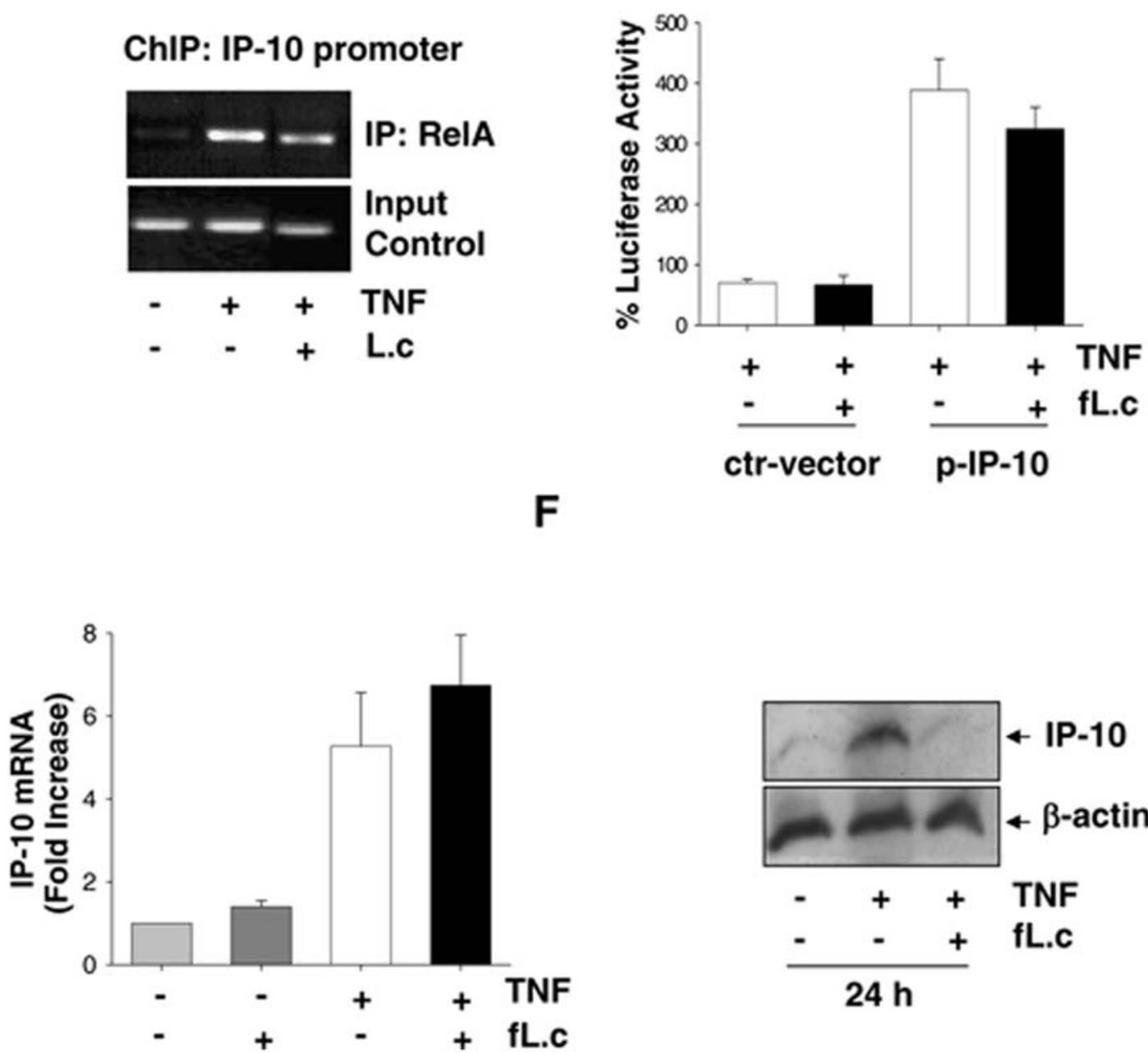

$24 \mathrm{~h}$

Figure 3. L. casei-induced inhibition of IP-10 secretion is mediated by a post-transcriptional mechanism (A) Mode-K cells were stimulated with TNF $(10 \mathrm{ng} / \mathrm{ml})$ and $L$. casei (moi 20) for 15 and $30 \mathrm{~min}$ and TNF-induced proteasomal degradation of IKB and (B) TNF-induced activation of RelA was analyzed by Western Blot in two independent experiments. (C) TNF-induced recruitment of NFkB RelA to the IP-10 promoter was analyzed in a ChIP experiment using an anti-RelA antibody after pre-incubation of Mode-K cells with $L$. casei (moi 20) (1h) and subsequent stimulation with TNF (10 ng/ml) for $2 \mathrm{~h}$. (D) Control (ctr-vector)- and IP-10 reporter (p-IP-10)-plasmid transfected Mode-K cells were stimulated with TNF $(10 \mathrm{ng} / \mathrm{ml}$ ) with or without $L$. casei (moi 20) and intracellular luciferase activity was measured by a luminescence assay after $24 \mathrm{~h}$. (E) Mode-K cells were stimulated with TNF (10 ng/ml) and/or L. casei (Moi 20) for $6 \mathrm{~h}$ followed by mRNA isolation, RT-PCR and qPCR. (F) Mode-K cells were stimulated with TNF (10 ng/ml) alone and together with L. casei (moi 20) for $24 \mathrm{~h}$. Intracellular accumulation of IP-10 was analyzed by Western blot and the shown figure is representative for more than three independent experiments. doi:10.1371/journal.pone.0004365.g003 
A

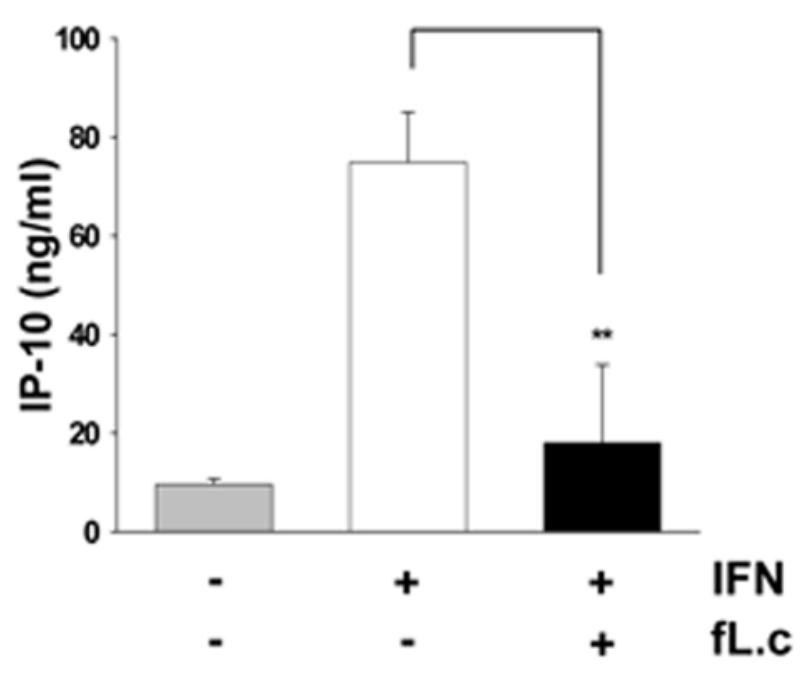

B
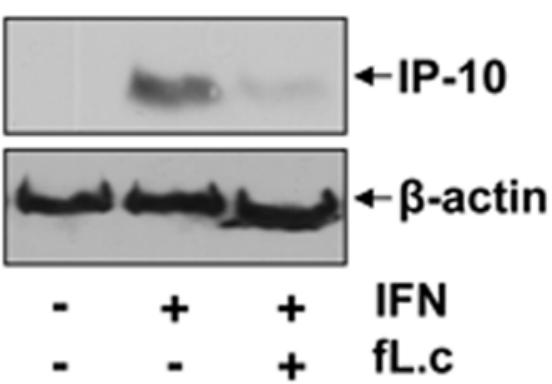

C

Secreted IP-10:

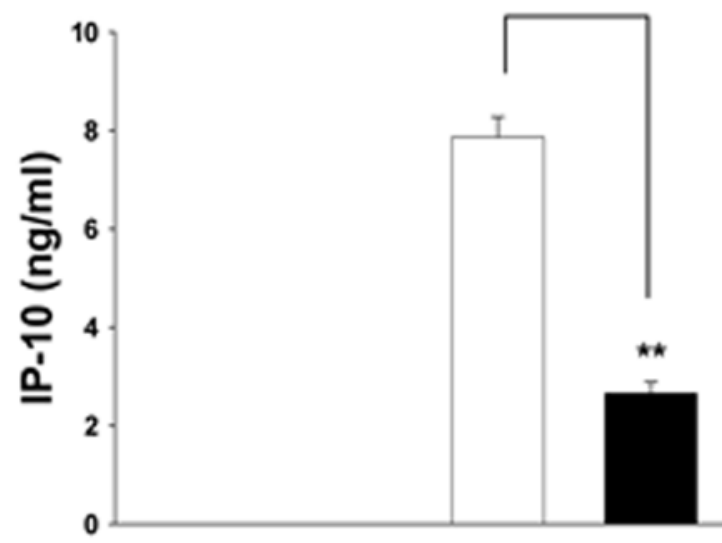

Intracellular IP-10:
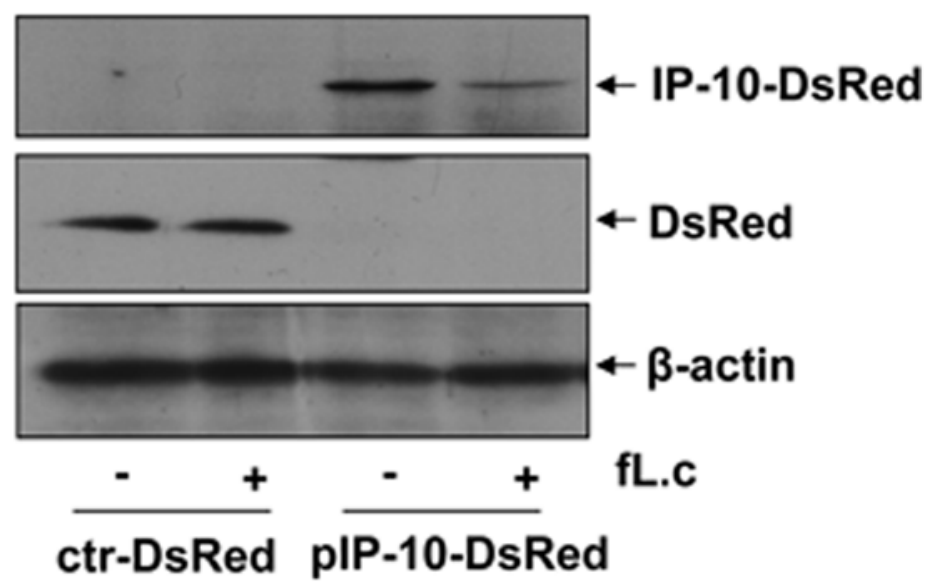
Figure 4. The inhibition of IP-10 secretion is independent of the signal-specific activation of IEC. (A) Mode-K cells were stimulated for $24 \mathrm{~h}$ with IFN $\gamma(100 \mathrm{ng} / \mathrm{ml}$ ) and L. casei (moi 20). Cell culture supernatants were analyzed by ELISA and (B) intracellular IP-10 protein levels by Western blot. (C) Mode-K cells were transfected with an IP-10 overexpression (pIP-10-DsRed)- or a ctr-DsRed-plasmid (transfection control) for $6 \mathrm{~h}$ and were then treated with L. casei for 24 h. IP-10 levels in the supernatants were determined by ELISA and intracellular DsRed-tagged IP-10 (IP-10-DsRed) or DsRed levels (transfection control) were determined by Western blot. Bars in A/C represent mean values (+/-SD) of triplicate samples and all figures are representative for three independent experiments. doi:10.1371/journal.pone.0004365.g004

either lysed in $200 \mu \mathrm{l}$ of 1xlysis buffer (Cell Signaling, Beverly, MA) supplemented with PMSF (1 mM) or they underwent a chase period of $3 \mathrm{~h}$ with or without stimulation with $L$. casei. After the chase period, cells were washed three times with $1 \times \mathrm{PBS}$ and lysed. Co-immunoprecipitation for IP-10 was performed as described and beads were resuspended in $20 \mu \mathrm{l}$ of Laemmli buffer for subsequent electrophoresis on a 15\% SDS gel. After drying the gel it was placed on a Kodak Storage Phosphor screen (Amersham bioscience) in a cassette (Amersham Bioscience) over night. The Storage Phosphor screen was then scanned by a Typhoon TRIO+ scanner (Amersham, Bioscience).

\section{Animals}

Conventionally raised $\mathrm{TNF}^{\triangle \mathrm{ARE}}$ mice (a generous gift from Kollias G., Institute for Immunology, Biomedical Sciences Research Center "Al. Fleming", Greece) on C57BL/6 background and SPF-raised IL-10 ${ }^{-/-}$mice on $129 \mathrm{SvEv}$ background as well as wildtype C57BL/6 and $129 \mathrm{SvEv}$ mice were fed 1,3 $\times 10^{9}$ cfu of VSL\#3 bacteria (a generous gift from Dr. DeSimone, VSL\#3 pharma, Italy) in 13,2\% (w/v) gelatine, $20 \%$ $(\mathrm{w} / \mathrm{v})$ glucose in water every weekday for 15 and 21 weeks starting at the age of three weeks. Placebo fed mice were used as controls, respectively. The gelatine was prepared freshly every third day. Mice were killed at the age of 18 and 24 weeks followed by sampling of gut content and IEC isolation. Sections of the distal ileum, cecal tip and distal colon were fixed in 10\% neutral buffered formalin (Sigma Aldrich). Fixed tissues were hematoxylinand eosin-stained and embedded in paraffin. Histology scoring was performed by blindly assessing the degree of lamina propria mononuclear cell infiltration, crypt hyperplasia, goblet cell depletion and architectural distortion, resulting in a score from 0 (not inflamed) to 12 (inflamed), as previously described [29]. Animal use was approved by the institution in charge (approval no. 55.2-1-S4-2531-74-06 and 32-2347/4+63).

\section{Isolation of primary mouse intestinal epithelial cells}

Primary IEC were purified as previously described [27]. Briefly, either ileal or cecal and colonic tissue was cut into pieces and incubated $\left(37^{\circ} \mathrm{C}, 15 \mathrm{~min}\right)$ in Mode- $\mathrm{K}$ cell culture media supplemented with $1 \mathrm{mM}$ dithiothreitol (Roth, Karlsruhe, Germany). The tissue/IEC suspensions were filtered, centrifuged (7 min, $300 \mathrm{~g}, \mathrm{RT}$ ) and cell pellets were resuspended in DMEM containing $5 \%$ fetal calf serum. The remaining tissue was incubated in $30 \mathrm{ml}$ PBS $\left(10 \mathrm{~min}, 37^{\circ} \mathrm{C}\right)$ containing $1.5 \mathrm{mM}$ EDTA (Roth, Karlsruhe, Germany). After filtration, the tissue was discarded and the cell suspension from this step was centrifuged as above. Finally, primary IEC were purified by centrifugation through a 20\%/40\% discontinuous Percoll gradient (GE Healthcare, Uppsala, Sweden) at $600 \mathrm{~g}$ for $30 \mathrm{~min}$. Primary IEC were collected in lysis buffer for subsequent Western blot analysis or in trizol for subsequent RNA isolation. Purity of IEC was confirmed by anti-CD3+-Western blot analysis.

DNA isolation from gut content and bacteria-specific PCR

Gut content DNA was extracted from $200 \mathrm{mg}$ of content using the QIAamp DNA Stool Mini Kit (Qiagen) according to the manfacturer's instructions. Streptococcus thermophilus (S. thermophilus) specific PCR of the 16S-23S rRNA gene spacer region was performed as described previously [30].

\section{Immunohistochemical labeling}

The cecum was dissected and immediately immersed in Tissue Tek OCT compound (Agar Scientific) and frozen in liquid nitrogen. Samples were stored under liquid nitrogen until analysed. $8 \mu \mathrm{m}$ sections were cut using a Leica CM1950 cryostat, picked up onto polylysine coated slides and air dried at room temperature for 45 minutes. Sections were fixed in $4 \%$ paraformaldehyde $0.1 \mathrm{M}$ phosphate buffer ( $\mathrm{pH} 7.4)$ for 5 minutes before being washed with 6 changes of PBS (pH 7.4) over 20 minutes. Slides were then incubated with $0.1 \%$ Triton $\times 100$ (Sigma) in PBS for 3 minutes before being washed as above. Fc receptors were blocked (Fc $\gamma$ III/II receptor from BD Pharminogen) and slides incubated in 10\% BSA 5\% normal donkey serum in PBS for $2 \mathrm{hrs}$ at room temperature. Blocking buffer was removed by capillary action and the slides incubated over night at $4{ }^{\circ} \mathrm{C}$ in either IP-10 goat polyclonal IgG (Santa Cruz G-15 sc-14641) or control goat IgG (Santa Cruz sc-2028) in 2\% BSA. The slides were washed with 6 changes of PBS over 1 hour. Alexa Fluor 488 donkey anti goat IgG (Invitrogen Molecular Probes) was applied to the sections and incubated for 30 minutes at room temperature. The slides were washed as above, counter stained with DAPI and mounted in vectashield (Vector laboratories). Sections were viewed on a Zeiss Axioskop microscope using a FITC and DAPI filter set and imaged using an QIMAGING camera.

\section{Statistical analysis}

Data were expressed as mean of triplicates $+/-$ standard deviation. Statistical tests were performed using two-tailed Student test for the in vitro experiments. The in vivo feeding studies were analysed using rank sum test. Differences were considered significant if values were $\left.<0.05{ }^{*}\right)$ or $<0.01(* *)$.

\section{Results}

VSL\#3-derived L. casei specifically inhibits TNF-induced secretion of chemotactically functional IP-10

To investigate the effects of VSL\#3 on pro-inflammatory IP-10 expression in IEC, we stimulated Mode-K cells with VSL\#3 bacteria (Moi 20) in the presence or absence of TNF, a potent inducer of IP-10 expression. The concentration of secreted IP-10 in the cell culture supernatant was analyzed by ELISA. VSL\#3 did not induce IP-10 expression. In contrast, VSL\#3 significantly reduced TNF-induced IP-10 but not IL-6 expression (Figure 1A, suggesting an IP-10 specific mechanism for the inhibitory function of IP-10. Besides, the stimulation of IEC with VSL\#3 bacteria alone induced IL-6 expression. A series of additional experiments with the eight VSL\#3 single bacterial strains (Moi 20) revealed that one of the eight strains, L. casei, exhibits analogous effects on IP-10 and IL-6 expression as the complex mixture VSL\#3 (Figure 1B). L. casei was therefore identified as the effective bacterial strain in the probiotic mixture concerning the observed cytokine expression profile. 
A

Intracellular IP-10:
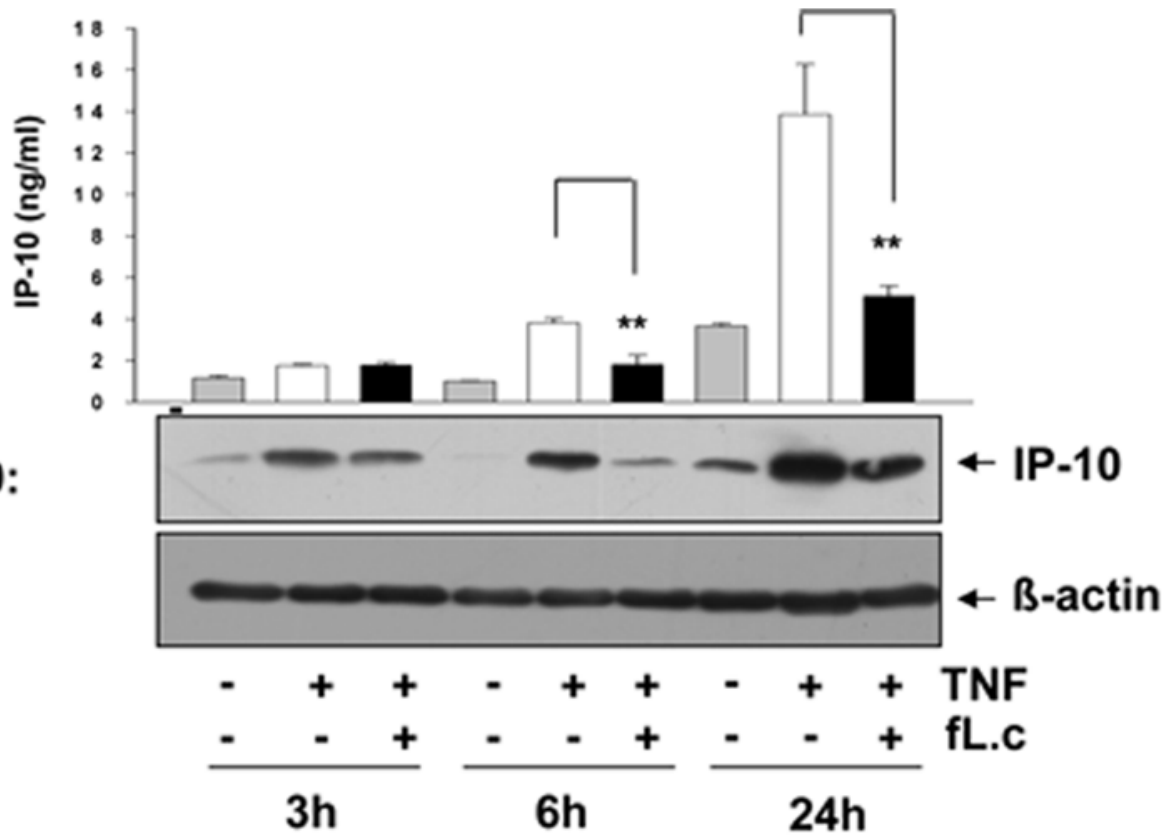

B

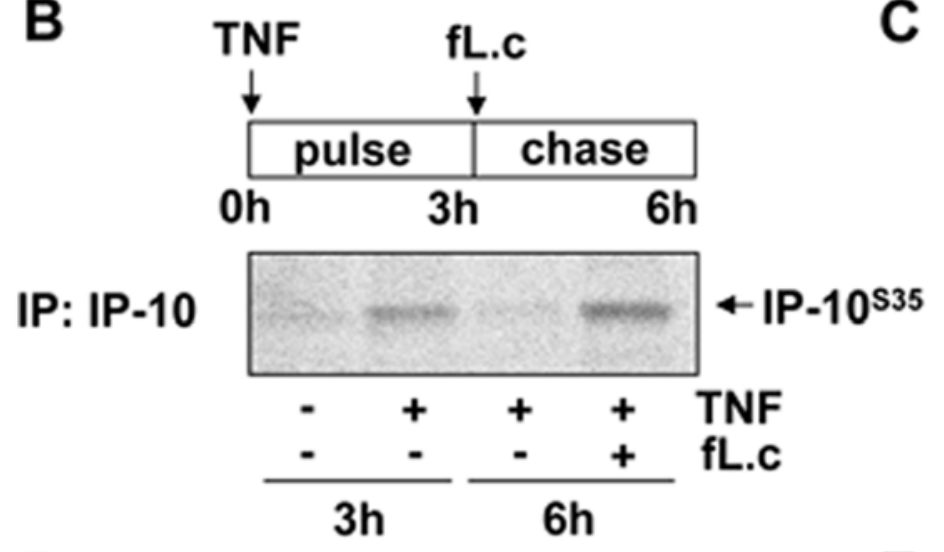

C

6h:

D

E

Co-IP: IP-10

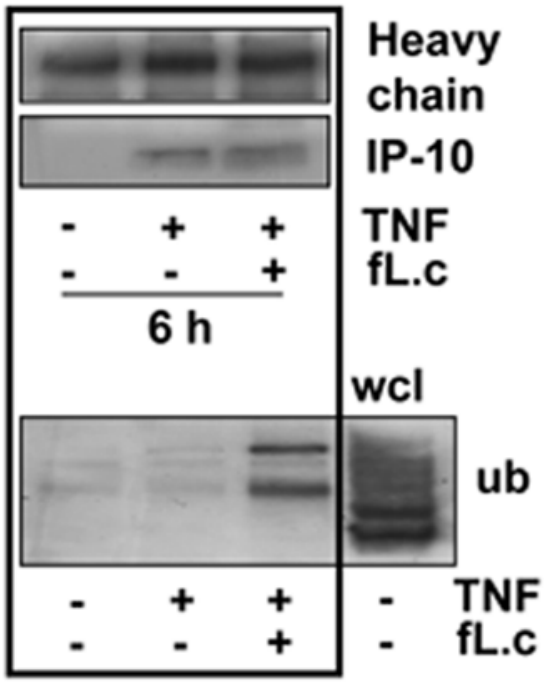

$\mathrm{wcl}=$ whole cell lysate
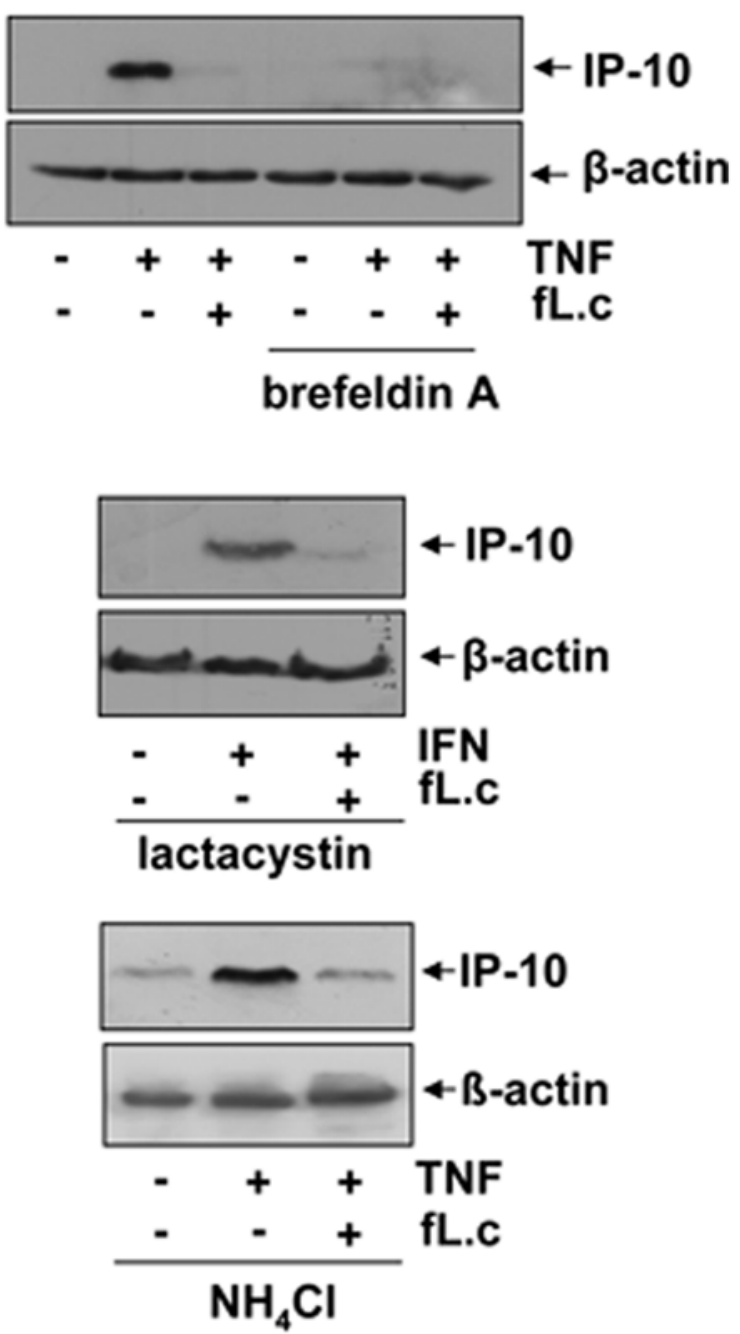
Figure 5. Degradation of IP-10 protein is the result of an IP-10 specific secretional blockade. (A) Mode-K cells were stimulated for 1, 3 or $24 \mathrm{~h}$ with TNF $(10 \mathrm{ng} / \mathrm{ml})$ alone or together with $L$. casei (moi 20) and intracellular as well as secreted levels of IP-10 were analyzed by Western Blot or ELISA analysis. Bars in A represent mean values $(+/-S D)$ of triplicate samples. The shown figure is representative for three independent experiments. (B) Mode-K cells were stimulated with TNF $(10 \mathrm{ng} / \mathrm{ml})$ during a $3 \mathrm{~h}$ pulse period ( $\mathrm{S}^{35}$-labelled cysteine/methionine, $\left.25 \mu \mathrm{Ci}\right)$ followed by a $3 \mathrm{~h}$ chase period in DMEM supplemented with L. casei (moi 20) or not. Subsequent immunoprecipitation for IP-10 was followed by protein separation on a $15 \%$ SDS gel. Intracellular levels of $\mathrm{S}^{35}$-labelled IP-10 were then made visible by a Phosphoimager plate. The shown figure is representative for two independent experiments. (C) Mode-K cells were stimulated with TNF $(10 \mathrm{ng} / \mathrm{ml})$ alone or together with $L$. casei in the presence or absence of brefeldin A $(0,5 \mu \mathrm{M})$. The amount of intracellular IP-10 after $6 \mathrm{~h}$ of stimulation was analyzed by Western blot. (D) Mode-K cells were stimulated for $6 \mathrm{~h}$ with TNF $(10 \mathrm{ng} / \mathrm{ml}$ ) alone or with $L$. casei (moi 20) before lysis and subsequent immunoprecipitation using an anti-IP-10 antibody was performed. Western blot was performed to investigate the presence of IP-10 and ubiquitine in the precipitated fractions (single experiment). (E) Mode-K cells were stimulated with IFN $\gamma(100 \mathrm{ng} / \mathrm{ml})$ or TNF $(10 \mathrm{ng} / \mathrm{ml})$ alone or together with L. casei (moi 20) in the presence of lactacystin or $\mathrm{NH}_{4} \mathrm{Cl}$ for $24 \mathrm{~h}$ and intracellular IP-10 was analyzed by Western blot. The shown figures are representative for three independent experiments.

doi:10.1371/journal.pone.0004365.g005

To analyze whether the observed inhibition of IP-10 has any functional consequence, we performed a $\mathrm{T}$ cell transmigration assay with Mode-K culture supernatants after a $24 \mathrm{~h}$ stimulation experiment. Figure $1 \mathrm{C}$ shows that TNF-conditioned media increases the transmigration of activated $\mathrm{T}$ cells whereas supernatants of IEC that were costimulated with $L$. casei did not exert this chemotactic effect. To show that the reduced transmigration rate in the $\mathrm{TNF} / L$. casei-conditioned media is due to the inhibition of IP-10 secretion by the probiotic bacteria, we used an IP-10 neutralizing antibody in the TNF-conditioned media. We demonstrated that the neutralization of IP-10 in this supernatant was sufficient to reduce the transmigration of $\mathrm{T}$ cells analogous to the effect of $L$. casei. These results clearly support the functional importance of the observed inhibition of IP-10 secretion in IEC by L. casei.

\section{Inhibition of TNF-induced IP-10 expression in IEC is mediated by a cell surface protein of $L$. casei}

Further analysis of other clinically relevant probiotic strains, Lactobacillus plantarum $299 \mathrm{v}$ and E. coli Nissle 1917, revealed that the inhibition of TNF-induced IP-10 secretion is dose-dependent and a unique feature of $L$. casei (Figure 2A). To investigate whether the inhibition of TNF-induced IP-10 expression was due to an active interaction between live L. casei and IEC, we inactivated $L$. casei by formaldehyde fixation, lysozyme lysis or heat treatment and subsequently stimulated Mode-K cells. Fig. 2B shows that fixed bacteria significantly inhibited TNF-induced IP-10 expression. However, lysis as well as heat-inactivation of $L$. casei resulted in complete loss of the observed inhibitory effect, suggesting a heatlabile surface structure of $L$. casei as the active bacterial component. To characterize this component in more detail, we treated $L$. casei with phospholipase A or the peptidases trypsine or proteinase $\mathrm{K}$. Subsequent bacterial stimulation of Mode-K cells revealed that both peptidases completely reversed the effect of $L$. casei on TNFinduced IP-10 expression. In contrast, phospholipase A treatment did not affect the inhibitory effects of $L$. casei (Figure 2C). These results demonstrated that the inhibition of TNF-activated IP-10 expression by $L$. casei is likely mediated through a cell surface protein. Consistently, the inhibition of TNF-induced IP-10 expression was not dependent on the pattern recognition receptor TLR2 (Figure 2D). Of note, the inhibition of IP-10 was dependent upon the presence of $L$. casei during TNF stimulation, since the preincubation of IEC with $L$. casei did not result in an inhibition of subsequently TNF-induced IP-10 expression (data not shown).

\section{L. casei induces post-transcriptional inhibition of TNF- induced IP-10 expression in IEC}

We were next interested in the molecular mechanism underlying the observed inhibitory effect of $L$. casei on IP-10 expression. Since the transcription factor NFKB plays an important role in the induction of IP-10 expression [31], we investigated whether $\mathrm{NF \kappa B}$ signaling might be impaired by stimulation of IEG with $L$. casei. As shown in Figure 3A, TNFinduced $\mathrm{I} \kappa \mathrm{B}$ degradation as well as TNF-induced RelA phosphorylation (Figure 3B) was not inhibited by L. casei. In addition, ChIP analysis revealed that TNF-induced recruitment of RelA to the IP-10 promoter was not affected by the probiotic bacteria (Figure 3C). To investigate whether the activation of any other relevant transcription factor was blocked by L. casei, we transfected Mode-K cells with an IP-10-promoter reporter gene construct and observed that TNF-induced IP-10 promoter-dependent luciferase expression was not inhibited by L. casei (Figure 3D). Consistent with unaffected IP-10 promoter activity, TNF-induced increase of IP-10 mRNA levels was not inhibited by L. casei (Figure 3E). In contrast to the elevated IP10 transcript level, Western blot analysis revealed that intracellular IP-10 protein was almost completely lost after 24 hours of costimulation with L. casei (Figure 3F).

\section{Inhibition of IP-10 secretion is independent of the signal- specific activation of IEC}

We next performed a stimulation experiment with $\operatorname{IFN} \gamma$, another potent inducer of IP-10 expression. As shown in Figure 4, IFN $\gamma$-induced IP-10 secretion (Figure 4A, ELISA analysis) and intracellular IP-10 protein expression (Figure 4B, Western blot analysis) was completely inhibited by $L$. casei. These results were analogous to the above described results observed under TNF-stimulation, suggesting that the inhibitory effects of $L$. casei were TNF-independent. To further characterize the signalspecificity of the inhibitory effect, we next performed a stimulation experiment with HEK293 cells that were transfected with a murine IP-10 overexpression plasmid resulting in constitutive expression of the chemokine. As shown in Figure 4C, L. casei significantly reduced intracellular and secreted levels of IP-10 in this experimental setup, whereas the production of the Ds-Redcontrol protein was not affected by the probiotic treatment. This result showed that the inhibitory effect of $L$. casei is indeed independent of the signal-specific activation pathways for IP-10, supporting our finding that the observed inhibition is mediated by a post-transcriptional mechanism.

\section{L. casei inhibits IP-10 secretion and triggers subsequent intracellular degradation of the chemokine}

We next investigated whether $L$. case $i$ had an inhibitory effect on IP-10 protein translation. As shown in Figure 1, general protein translation and secretion was not impaired by the probiotic bacteria as indicated by normal or even increased secretion of other cytokines/chemokines like IL-6 (Figure 1A/B) or MIP-2 (data not shown). Western blot analysis of intracellular IP-10 protein levels revealed that TNF-induced IP-10 protein expression was not inhibited by $L$. casei at early time points (3h after costimulation). In contrast, the loss of intracellular IP-10 protein was detectable after 6 to $24 \mathrm{~h}$ of costimulation although it was not 


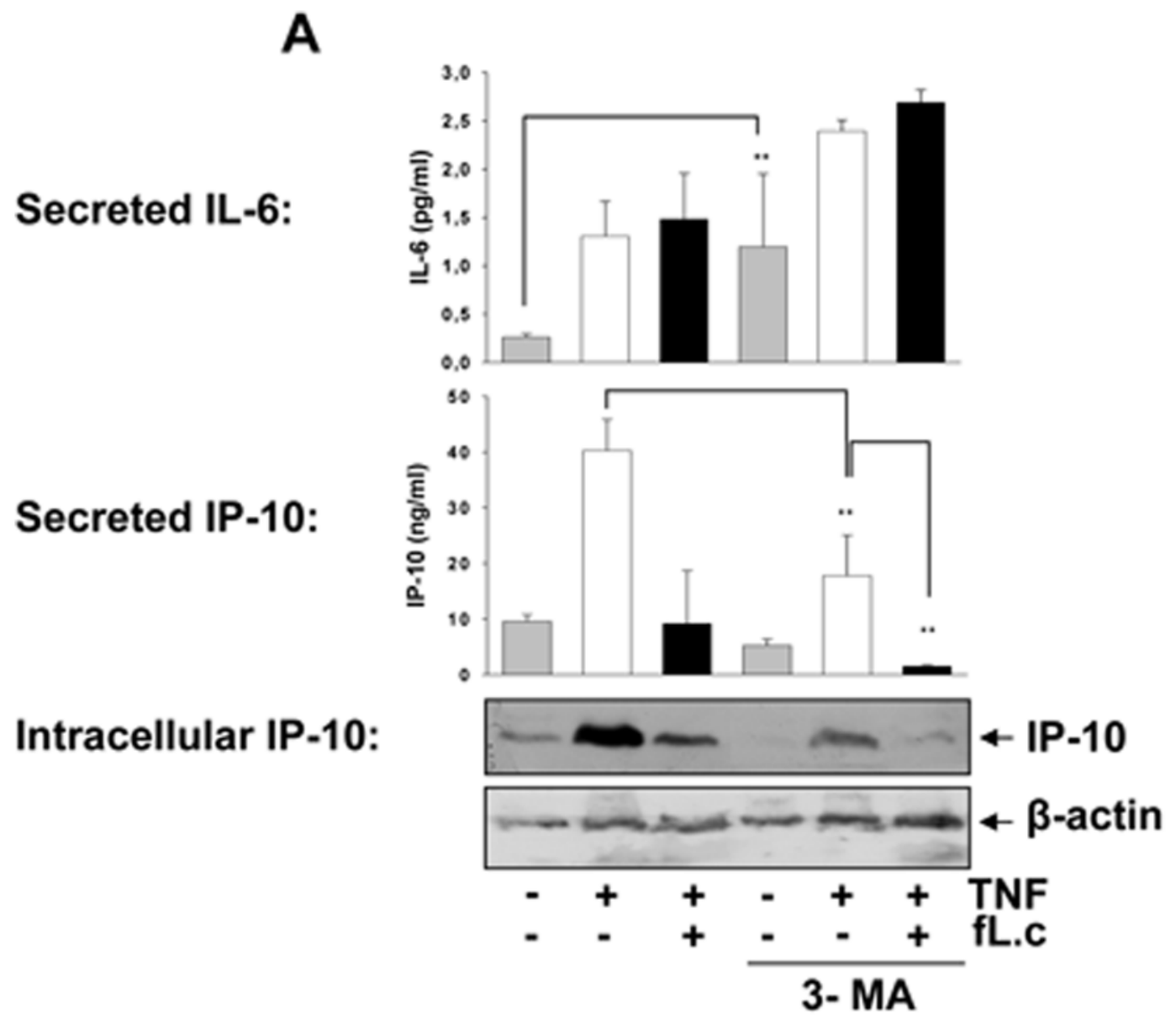

B

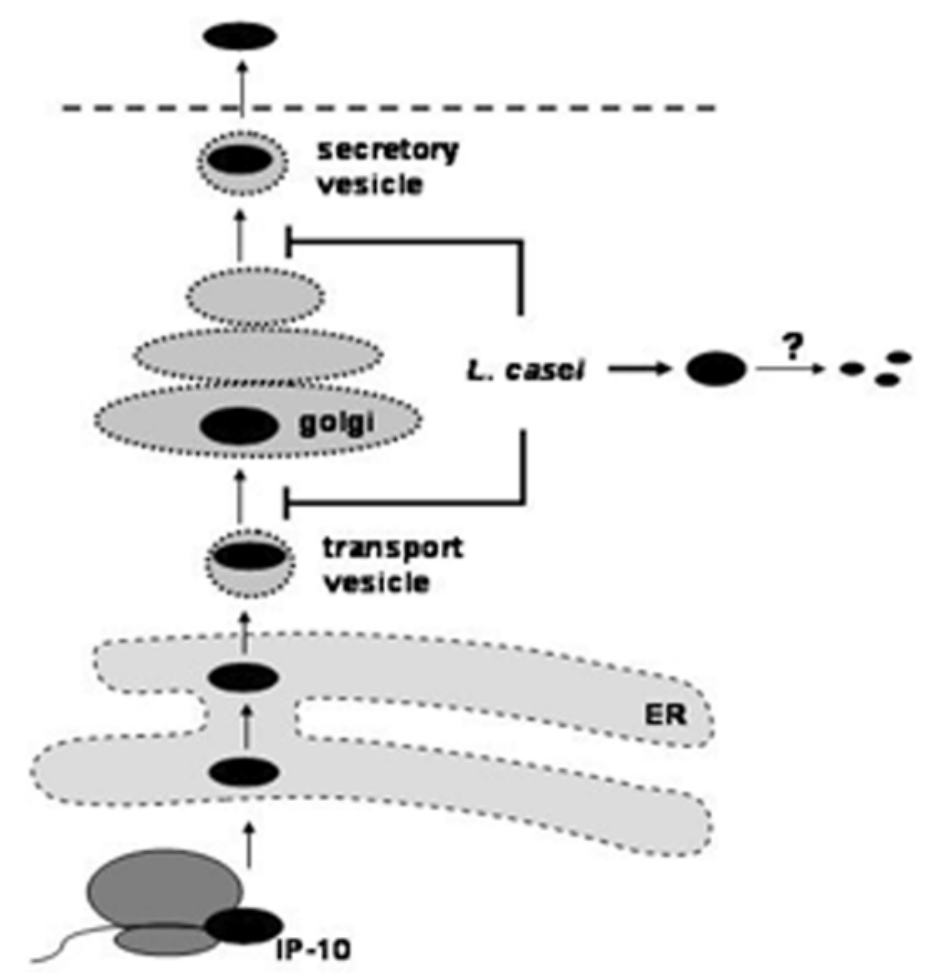


Figure 6. Blockade of 3-MA-dependent vesicular transport by L. casei might induce the degradation of IP-10. (A) Mode-K cells were stimulated with TNF $(10 \mathrm{ng} / \mathrm{ml})$ alone or together with L. casei (moi 20) in the presence or absence of 3-MA for $24 \mathrm{~h}$ and the amount of IP-10 in the cell culture supernatant as well as intracellularly was analyzed by ELISA and Western blot. Figure $A$ is representative for three independent experiments and bars represent mean values (+/-SD) of triplicate samples. (B) The scheme illustrates our hypothesis that L. casei might target 3-MA dependent vesicular transport of IP-10 resulting in a secretional blockade and subsequent degradation of the chemokine. doi:10.1371/journal.pone.0004365.g006

secreted into the cell culture supernatant (Figure 5A). This result demonstrated that initial TNF-induced IP-10 translation is not targeted by the probiotic bacteria suggesting that the observed loss of IP-10 protein is due to post-translational degradation. To further analyse the fate of initially produced IP-10 protein in more detail, we performed a $\mathrm{S}^{35}$ pulse-chase labelling experiment. Interestingly, IP-10 immunoprecipitation experiments showed that TNF-induced $\mathrm{S}^{35}$-IP-10 protein, that was produced during the initial $3 \mathrm{~h}$ pulse period, was absent in Mode-K cells after the subsequent $3 \mathrm{~h}$ chase period, demonstrating the functionality of the secretion system. In contrast, TNF-induced $\mathrm{S}^{35}$-IP-10 was still detectable intracellularly after the chase period in Mode-K cells that were costimulated during the chase period (Figure 5B). This result clearly showed that $L$. casei prevents the secretion of IP-10 protein. However, this finding was in sharp contrast to the observation that IP-10 protein is lost intracellularly at later time points instead of intracellular accumulation as it would be expected to be the result of a secretional blockade. To further analyze this discrepancy, we performed TNF and $L$. casei c(o)stimulation experiments in the presence of brefeldin A, a known inhibitor of vesicular transport from the endoplasmic reticulum to the golgi network. Surprisingly, we found that the inhibition of the protein export machinery by brefeldin A resulted in complete loss of intracellular IP-10 protein analogous to the results described above in the costimulation experiments with $L$. casei (Figure 5C). This result confirms that indeed, a secretional blockade of IP-10 results in subsequent loss of intracellular IP-10 protein, suggesting the initiation of degradative mechanisms as a consequence of initial IP-10 accumulation.

We next addressed the question which degradation pathway might be responsible for the observed loss of IP-10 protein in IEC. Co-immunoprecipitation analysis revealed that IP-10 was ubiquitinated in the presence of $L$. casei (Figure 5D) indicating proteasomal degradation. Since TNF-induced IP-10 expression depends on proteasomal I $\kappa \mathrm{B}$ degradation, we stimulated cells with IFN $\gamma$ to investigate the effect of proteasomal inhibition on IP-10 degradation. Figure 5E shows that stimulation with the proteasomal inhibitor lactacystin did not rescue IFN $\gamma$-induced IP-10 protein from degradation. Next, we investigated whether IP-10 protein was degraded through lysosomal pathways. The inhibition of lysosomal degradation by $\mathrm{NH}_{4} \mathrm{Cl}$ (Figure $5 \mathrm{E}$ ) did not prevent the loss of IP-10 protein, suggesting an additional proteolytic mechanism for IP-10 degradation.

\section{L. casei mimicks the effects of the inhibition of autophagic-lysosomal pathways on cytokine/chemokine expression}

To investigate whether autophagic-lysosomal degradation pathways might play a role in the observed loss of IP-10 protein, we applied TNF and $L$. casei to the epithelial cell culture in the presence of 3-methyladenine (3-MA). Surprisingly, we demonstrated that the stimulation of IEC with 3-MA, which is a known inhibitor of vesicle formation in the context of autophagylysosomal degradation, did not prevent the loss of intracellular IP-10 (Figure 6A, Western blot analysis), but rather mimicked the effects of $L$. casei on the TNF-induced cytokine secretion pattern
(Figure 6A, ELISA analysis). Figure 6A shows that 3-MA decreased the level of IP-10 protein intracellularly as well as in the cell culture supernatant. In contrast, TNF-induced IL-6 secretion was not inhibited in the presence of 3-MA. These observations indicated that IP-10 but not IL-6 secretion is dependent on the formation of secretory vesicles that can be inhibited by 3-MA. We therefore hypothesize that L. casei impairs 3-MA-dependent vesicular trafficking resulting in disturbed IP-10 secretion and subsequent degradation of IP-10 protein (Figure 6B).

The protective activity of VSL\#3 on experimental colitis is intestinal segment specific and correlates with IP-10 expression in IEC

To evaluate the physiological impact of VSL\#3 on experimental intestinal inflammation, we performed probiotic feeding studies with heterozygous $\mathrm{TNF}^{\triangle \mathrm{ARE}}$ mice, an animal model for TNFinduced experimental ileitis [32], and IL- $10^{-/-}$mice, an animal model for experimental colitis [33]. $\mathrm{TNF}^{\triangle \mathrm{ARE}}$ mice, IL-10 ${ }^{-1-}$ mice and wildtype mice were fed VSL\#3 $\left(1.3 \times 10^{9}\right.$ cfu per mouse/day) for 15 and 21 weeks post-weaning. Histopathological analysis of distal ileal sections revealed that VSL\#3 did not inhibit the development of severe ileal inflammation in $\mathrm{TNF}^{\triangle \mathrm{ARE}}$ mice (Figure 7A). As expected, we found that TNF-induced ileitis correlates with enhanced IP-10 protein expression in primary ileal epithelial cells from $\mathrm{TNF}^{\Delta \mathrm{ARE}}$ mice. The absence of $\mathrm{T}$-cell contaminations in the purified IEC from inflamed mice confirmed the purity of the epithelial cell isolation (data not shown). Consistent with the tissue pathology, VSL\#3 did not reduce IP10 protein expression in primary ileal IEG (Figure 7B). The presence of VSL\#3 bacteria in the intestine was proven by the use of bacteria-specific PCR on DNA isolated from intestinal contents (Figure 7C). In contrast to the unresponsiveness of heterozygous $\mathrm{TNF}^{\triangle \mathrm{ARE}}$ mice to VSL\#3 treatment, we found that cecal (Figure 8A) but not colonic (Figure 8B) inflammation in IL-10 ${ }^{-/-}$ mice was significantly reduced by the probiotic mixture, suggesting intestinal segment specific effects of VSL\#3. In consistence with the results derived from $\mathrm{TNF}^{\triangle \mathrm{ARE}}$ mice, we detected elevated levels of IP-10 in isolated intestinal epithelial cells of IL-10 ${ }^{-1-}$ mice compared to wildtype mice. Although we were not able to separate cecal and colonic epithelial cells during the isolation procedure (for the sake of yield), Western blot analysis showed that VSL\#3 clearly reduced the expression of IP-10 even in the pooled cell population. Real-time PCR analysis of IP-10 mRNA levels in these primary IECs showed that the observed reduction of IP-10 protein is not due to reduced levels of IP-10 mRNA (Figure 8C), supporting our finding that the reduction of IP-10 protein in IEC is the result of a post-transcriptional mechanism induced by VSL\#3. Most importantly, immunohistochemical staining of IP-10 in cecal tissue sections confirmed that VSL\#3 strongly reduced IEC-specific IP-10 expression in the cecum of IL10 ${ }^{-}>-$mice (Figure 8D).

\section{Discussion}

The present study shows for the first time bacterial strainspecific effects of the clinically relevant probiotic mixture VSL\#3 on the expression of a pro-inflammatory chemokine in primary 
A

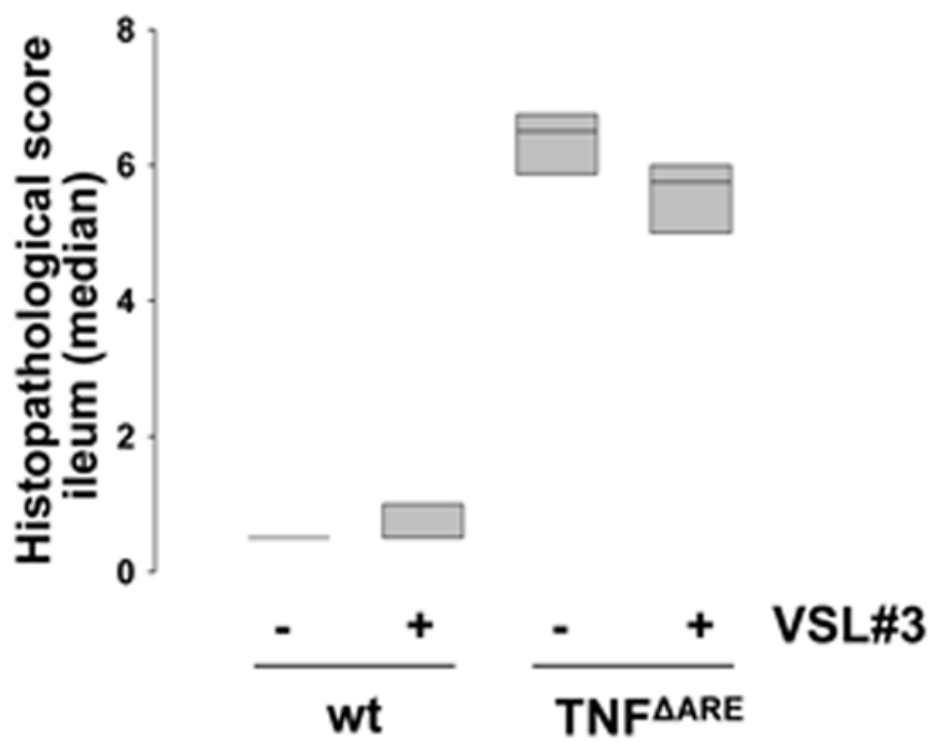

B

Ileal epithelial cells:

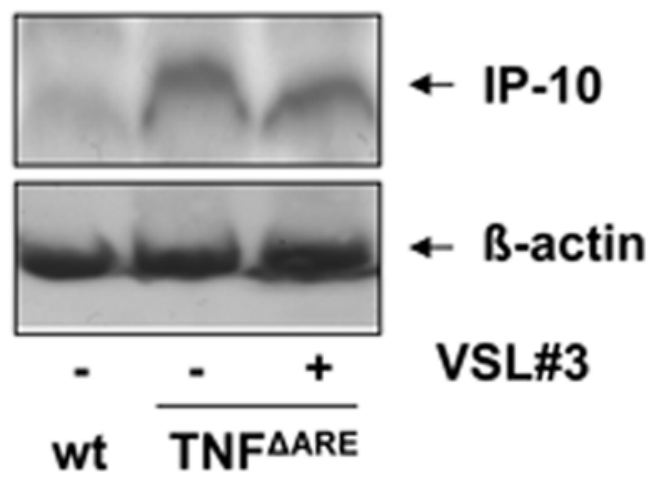

C

S. thermophilus

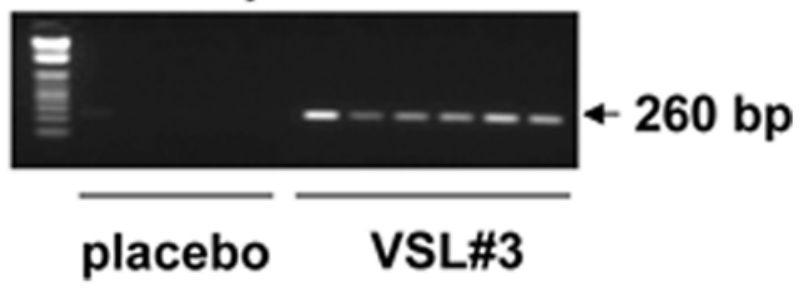


Figure 7. VSL\#3 does not reduce experimental ileitis in $\operatorname{TNF}^{\triangle A R E}$ mice. TNF ${ }^{\triangle A R E}(n=6)$ and wt mice $(n=5)$ were fed VSL\#3 $\left(1,3 \times 10^{9} \mathrm{cfu} /\right.$ mouse/day) or placebo for 15 weeks. Mice were sacrificed at 18 weeks of age and histopathological scoring was performed by blindly assessing the

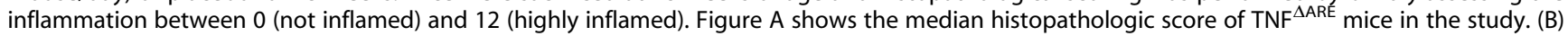
Ileal IEC were isolated and pooled proteins $(50 \mu \mathrm{g})$ of all mice in a group were analyzed for IP-10 expression by Western blot. (C) The presence of VSL\#3 derived S. thermophilus (S.t) in the gut of the TNF ${ }^{\triangle A R E}$ mice was examined by bacteria-specific PCR analysis. doi:10.1371/journal.pone.0004365.g007

IEG and IEG lines. VSL\#3-derived L. casei was identified to inhibit TNF-induced IP-10 expression to the same extent as the complex probiotic mixture. This effect was found to be a unique feature of VSL\#3-derived L. casei as other clinically relevant probiotic bacteria like L. plantarum 299 and E. coli Nissle 1917 did not reduce IP-10 secretion. Since formaldehyde fixed $L$. casei had the same inhibitory effect on IP-10 secretion as live bacteria, active interaction between bacteria and IEC is not necessary for the inhibitory effect, suggesting a bacterial cell surface component as the effective probiotic structure. In contrast to L. rhamnosus GG, a probiotic bacteria that was shown to have protective effects on IEC survival and growth via two secreted proteins [34], we demonstrated that the inhibition of TNF-induced IP-10 secretion was due to a heat-labile surface protein of $L$. casei. The proteinasous nature of the bacterial structure responsible for the inhibition of IP-10 was supported by the finding that the effect was independent of TLR2-dependent signalling mechanisms. Stimulation experiments with IFN $\gamma$ and IP-10 overexpression experiments revealed stimuli-independent mechanisms to underly the inhibition of IP-10 expression by $L$. casei. Given the high physiological relevance of elevated IP-10 expression in inflamed intestinal tissue regions of IBD patients and animal models of experimental colitis [20-22], the inhibitory effect on this chemokine may play an important role in the anti-inflammatory effects of the probiotic mixture VSL\#3 on inflammatory bowel diseases [9]. We were able to show that IP-10 expression in IEC correlates with inflammation, as IP-10 expression was elevated in primary ileal IEC from heterozygous $\mathrm{TNF}^{\triangle \mathrm{ARE}}$ mice as well as in colonic IEC from IL- $10^{-/-}$mice compared to healthy wildtype mice. In a healthy host, pathogen-induced secretion of IP-10 triggers enhanced recruitment of effector Thl cells and monocytes into the mucosa, resulting in subsequent deletion of the infectious agent. In the case of IBD, chronically activated IEC steadily produce high amounts of IP-10 in the absence of any pathogenical stimuli resulting in constant Thl and monocyte recruitment. The presence and activity of these effector cells may lead to the loss of epithelial cell integrity and tissue damage. In consequence, the expression of IP-10 in IEC has to be tightly regulated to prevent infections on the one hand and the development of pathological conditions like chronic intestinal inflammations on the other hand. Consistently, IP-10 expression has been shown to be modulated at various levels. The activation of $\operatorname{PPAR} \gamma$ by $\operatorname{PPAR} \gamma$ ligands inhibited IP-10 expression by reducing IP-10 promoter activity [35]. In addition, butyrate inhibited IFN $\gamma$ and TNF-induced IP-10 transcription in colonic subepithelial myofibroblasts [36] and interleukin 10 suppressed LPS-induced IP-10 gene transcription in peritoneal macrophages [37]. Many studies have analyzed the transcriptional regulation of cytokines and chemokines like IP-10 but although post-transcriptional and post-translational regulation of chemokines is suggested to be very important [38], exact mechanisms are mostly unknown. The pro-inflammatory chemokine interleukin 8 was shown to be upregulated by a TLR5mediated, p38-dependent post-transcriptional mechanism [39] and furthermore, to be processed at the amino terminal end by a matrix metallo proteinase [40]. In addition, the biosynthesis of IFN $\gamma$ was shown to be suppressed post-transcriptionally by the stimulation with lead [41]. Concerning IP-10, complex post-transcriptional regulatory mechanisms seem to play an important role. Recent studies revealed regulatory mechanisms like IP-10 mRNA half-life modulation in monocytes [42] or Cterminal truncation through furin, a pro-protein convertase, resulting in another active form of the chemokine [43]. Furthermore, IP-10 was found to be processed C-terminally by gelatinase B and neutrophil collagenase [40]. In addition, the activity of IP-10 was shown to be regulated by its oligomerization status [44]. Our study revealed for the first time that probiotic bacteria are able to induce post-translational regulation of IP-10 protein in IEC. Decreased IP-10 protein stability was identified as a new post-translational regulatory mechanism.

L. case $i$-induced ubiquitination of IP-10 is very likely involved in the observed degradation of the chemokine although it does not target the protein for proteasomal degradation. It has already been shown that stimulation with $L$. casei has multiple effects on the expression of genes involved in proteasome and ubiquitination pathways in IEC [45], but the exact mechanisms are not known yet. In contrast to lysosomal degradation of LPS-induced TNF under hypoxia [46], lysosomal pathways were not involved in $L$. casei-induced loss of IP-10 protein, suggesting alternative degradation pathways to be involved. The inhibition of protein secretion through brefeldin A was found to induce degradation of IP-10 instead of intracellular accumulation, as it was shown for other secretory proteins like makrophage inflammatory protein-2 [47]. This result led to the hypothesis that $L$. casei might selectively impair secretion of IP-10 followed by subsequent degradation as a protective mechanism to prevent protein accumulation. In contrast to interleukin-6, the secretion of IP-10 was found to be dependent on tightly regulated vesicular transport. $L$. casei mimicks the effect of 3-methyladenine, an inhibitor of vesicular trafficking and exosome secretion [48], which specifically inhibits IP-10 secretion and induces loss of intracellular IP-10 protein. Considering the extensive post-translational processing of IP-10, this inhibitory mechanism might be due to the necessity for chemokine maturation processes in endo-lysosomal compartments prior to exocytosis as it has been shown for several other secretory proteins $[49,50]$. We therefore hypothesize that $L$. casei inhibits vesicle trafficking similar to 3-methyladenine, resulting in impaired maturation and secretion of IP-10 followed by subsequent degradation of the chemokine (Figure 6B).

Our in vivo feeding studies revealed that VSL\#3 has no effect on the development of ileal inflammation in heterozygous $\mathrm{TNF}^{\Delta \mathrm{ARE}}$ mice. This result may indicate that the constant overexpression of TNF in these mice and the resulting T-cell driven immunopathology constitute such a strong pro-inflammatory stimulus that probiotic therapy is not sufficient to reduce tissue inflammation. Apart from that, one could raise the hypothesis that probiotic therapy is generally less effective in the ileum than in the colon due to high luminal content passage rates in this intestinal segment. The failure of VSL\#3 in the context of ileitis together with the observed reduction of cecal inflammation in $\mathrm{IL}-10^{-/-}$mice is consistent with clinical data showing effective probiotic treatment mostly in the context of UC [9] and pouchitis patients [51]. The finding that VSL\#3 has protective effects on cecal but not on colonic inflammation clearly reveals intestinal segment specific effects of the probiotic mixture. The differences in response to 
A

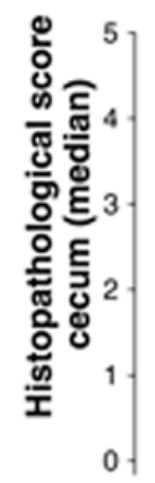

C

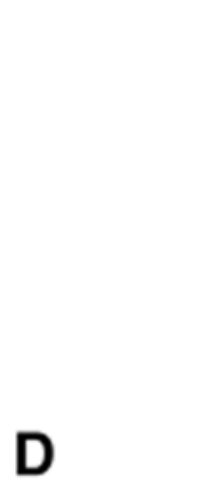$$
\text { 4 IP-10 }
$$
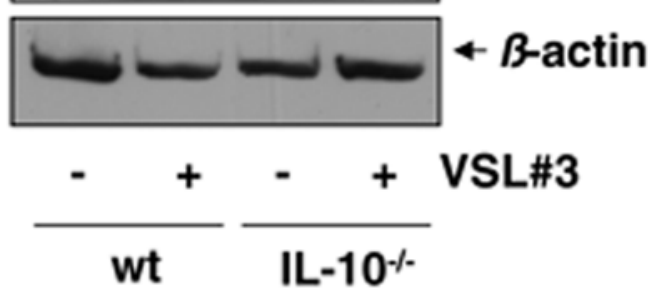

Cecal tissue sections:
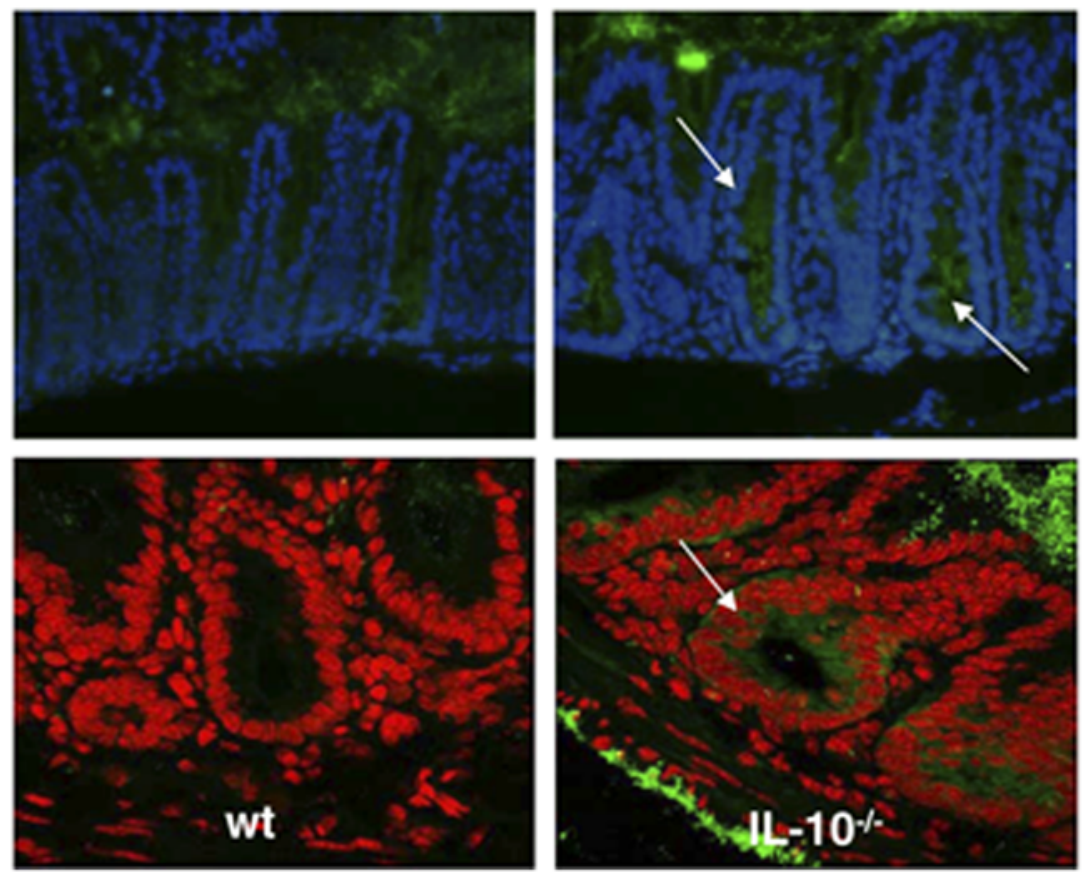

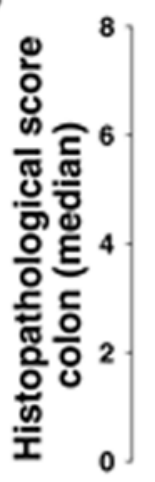

$\frac{-}{w t} \frac{-}{\mathrm{IL}-10 \%}$ VSL\#3
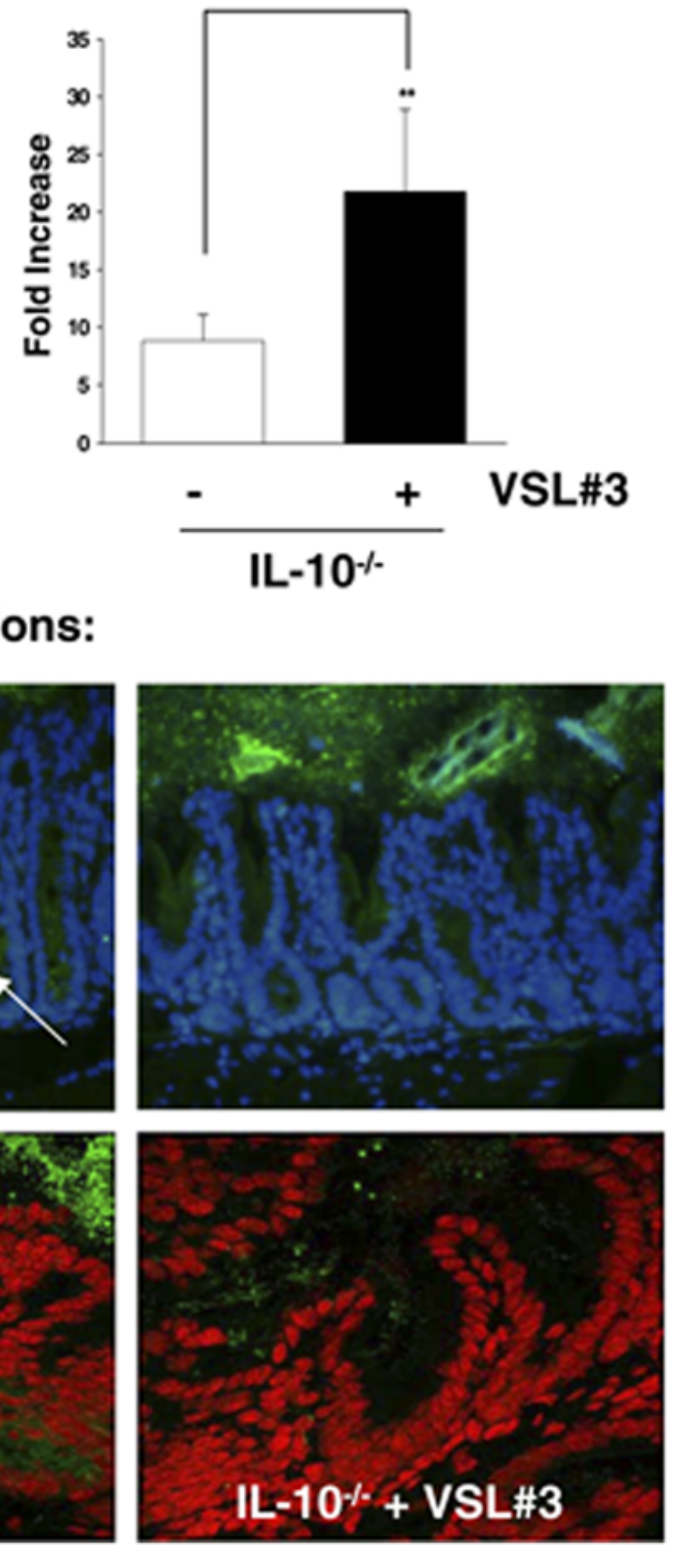
Figure 8. Intestinal segment specific effects of VSL\#3 on experimental inflammation correlate with IP-10 expression in IEC. IL-10 ${ }^{-/-}$ mice were fed VSL\#3 $\left(1,3 \times 10^{9} \mathrm{cfu} /\right.$ mouse/day) $(n=14)$ or placebo $(n=12)$ analogous to wt mice $(n=9)$ for 21 weeks. Mice were sacrificed at 24 weeks of age and histopathological scoring was performed by blindly assessing the inflammation between 0 (not inflamed) and 12 (highly

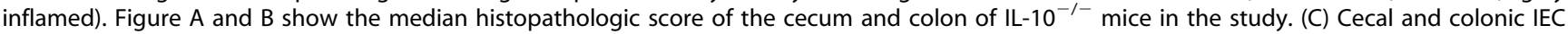
were isolated together and proteins $(50 \mu \mathrm{g})$ as well as mRNA of all mice in a group were analyzed for IP-10 expression by Western blot or RT-PCR (D) Immunohistochemical staining of IP-10 in cecal tissue sections was performed. The upper row shows representative pictures (three mice per group were analysed) of stained tissue sections (IP-10 (green), DAPI (blue)) and the lower row shows representative false colour confocal images of the stained tissue sections ((IP-10) green, DAPI (red)). Arrows indicate regions that show elevated IP-10 expression.

doi:10.1371/journal.pone.0004365.g008

probiotic treatment between the two intestinal compartments might be due to the lower inflammatory grade in the cecum compared to the colon in IL-10 $10^{-/-}$mice or due to differences in the bacterial colonisation. The discrepancy to previously published studies, showing anti-inflammatory effects of VSL\#3 in the cecum and colon [15], may presumably be due to differences in the composition of the intestinal microbiota of the IL- $10^{-/-}$mice in different animal facilities or the time point of intervention. The intestinal microbiota has already been shown to have an enormous impact upon the onset, severity and localisation of experimental colitis, suggesting that even small differences might impact the effectiveness of probiotic treatment [52].

The expression of IP-10 in primary intestinal epithelial cells was found to correlate strongly with disease severity. Consistent with the finding that injection of an anti-IP-10 antibody leads to the attenuation of colitis in IL-10 $0^{-/-}$mice [21], our study revealed that the post-transcriptional inhibition of IP-10 secretion in cecal

\section{References}

1. Loftus E (2004) Clinical epidemiology of inflammatory bowel disease: Incidence, prevalence, and environmental influences. Gasteroenterology 126 : 1504-1517.

2. Cho JH (2008) The genetics and immunopathogenesis of inflammatory bowel disease. Nat Rev Immunol 8: 458-466.

3. Sartor RB (2008) Microbial influences in inflammatory bowel diseases. Gastroenterology 134: 577-594.

4. Gionchetti P, Rizzello F, Helwig U, Venturi A, Lammers KM, et al. (2003) Prophylaxis of pouchitis onset with probiotic therapy: a double-blind, placebocontrolled trial. Gastroenterology 124: 1202-1209.

5. Gionchetti P, Rizzello F, Morselli C, Poggioli G, Tambasco R, et al. (2007) High-dose probiotics for the treatment of active pouchitis. Dis Colon Rectum 50: 2075-2082; discussion 2082-2074.

6. Kruis W, Fric P, Pokrotnieks J, Lukas M, Fixa B, et al. (2004) Maintaining remission of ulcerative colitis with the probiotic Escherichia coli Nissle 1917 is as effective as with standard mesalazine. Gut 53: 1617-1623.

7. Rembacken BJ, Snelling AM, Hawkey PM, Chalmers DM, Axon AT (1999) Non-pathogenic Escherichia coli versus mesalazine for the treatment of ulcerative colitis: a randomised trial. Lancet 354: 635-639.

8. Isaacs K, Herfarth H (2008) Role of probiotic therapy in IBD. Inflamm Bowel Dis 14: 1597-1605.

9. Bibiloni R, Fedorak RN, Tannock GW, Madsen KL, Gionchetti P, Campieri M, De Simone C, Sartor RB (2005) VSL\#3 probiotic mixture induces remission in patients with active ulcerative colitis. Am J Gastroenterol. 100: 1539-1546.

10. Pronio A, Montesani C, Butteroni C, Vecchione S, Mumolo G, et al. (2008) Probiotic administration in patients with ileal pouch-anal anastomosis for ulcerative colitis is associated with expansion of mucosal regulatory cells. Inflamm Bowel Dis 14: 662-668.

11. Gionchetti P, Rizzello F, Venturi A, Brigidi P, Matteuzzi D, et al. (2000) Oral bacteriotherapy as maintenance treatment in patients with chronic pouchitis: a double-blind, placebo-controlled trial. Gastroenterology 119: 305-309.

12. Mimura T, Rizzello F, Helwig U, Poggioli G, Schreiber S, et al. (2004) Once daily high dose probiotic therapy (VSL\#3) for maintaining remission in recurrent or refractory pouchitis. Gut 53: 108-114.

13. Soo I, Madsen KL, Tejpar Q, Sydora BC, Sherbaniuk R, et al. (2008) VSL\#3 probiotic upregulates intestinal mucosal alkaline sphingomyelinase and reduces inflammation. Can J Gastroenterol 22: 237-242.

14. Tursi A, Brandimarte G, Giorgetti GM, Forti G, Modeo ME, et al. (2004) Lowdose balsalazide plus a high-potency probiotic preparation is more effective than balsalazide alone or mesalazine in the treatment of acute mild-to-moderate ulcerative colitis. Med Sci Monit 10: PI126-131.

15. Madsen K, Cornish A, Soper P, McKaigney C, Jijon H, et al. (2001) Probiotic bacteria enhance murine and human intestinal epithelial barrier function. Gastroenterology 121: 580-591. epithelial cells by VSL\#3 is paralleled by reduced cecal inflammation. Our findings demonstrate that the inhibition of IP-10 secretion by VSL\#3 is an important molecular mechanism contributing to the anti-inflammatory effect of the clinically relevant probiotic mixture.

\section{Acknowledgments}

We thank M.Sc. Emanuel Berger, Dipl. Ing. Christine Bäuerl, Mrs Margaret Delday and Dr. Klaus-Peter Janssen for their contributions to the manuscript.

\section{Author Contributions}

Conceived and designed the experiments: GH DK GL MB DH. Performed the experiments: GH TG MH CR GL GH ML. Analyzed the data: GH. Contributed reagents/materials/analysis tools: MB ML DH. Wrote the paper: GH.

16. Petrof KK, Ropeleski MJ, et al. (2004) Probiotics inhibit nuclear factor-kappaB and induce heat shock proteins in colonic epithelial cells through proteasome inhibition. Gastroenterology 127: 1474-1487.

17. Giacinto C, Marinaro M, Massimo S, Strober W, Boirivant M (2005) Probiotics ameliorate recurrent Th1-mediated murine colitis by inducing IL-10 and IL-10dependent TGF-B-bearing regulatory cells. Journal of Immunology 174: 3237-3246.

18. Artis D (2008) Epithelial-cell recognition of commensal bacteria and maintenance of immune homeostasis in the gut. Nat Rev Immunol 8: 411-420.

19. Clavel T, Haller D (2007) Bacteria- and host-derived mechanisms to control intestinal epithelial cell homeostasis: implications for chronic inflammation. Inflamm Bowel Dis 13: 1153-1164.

20. Banks C, Bateman A, Payne R, Johnson P, Sheron N (2003) Chemokine expression in IBD. Mucosal chemokine expression is unselectively increased in both ulcerative colitis and Crohn's disease. J Pathol 199: 28-35.

21. Hyun J, Lee G, Brown JB, Grimm GR, Tang Y, Mittal N, Dirisina R, Zhang Z, FryerJP, Weinstock JV, Luster AD, Barrett TA (2005) Anti-interferon-inducible chemokine, CXCL10, reduces colitis by impairing T helper-1 induction and recruitment in mice. Inflamm Bowel Dis 11: 799-805.

22. Suzuki K, Kawauchi Y, Palaniyandi SS, Veeraveedu PT, Fujii M, Yamagiwa S, Yoneyama H, Han GD, Kawachi H, Okada Y, Ajioka Y, Watanabe K, Hosono M, Asakura H, Aoyagi Y, Narumi S (2007) Blockade of interferongamma-inducible protein-10 attenuates chronic experimental colitis by blocking cellular trafficking and protecting intestinal epithelial cells. Pathol Int 57: $413-420$.

23. Kamada N, Maeda K, Inoue N, Hisamatsu T, Hibi T (2008) Nonpathogenic Escherichia coli strain Nissle 1917 inhibits signal transduction in intestinal epithelial cells. Infect. Immun. 76: 214-220.

24. Otte JM, Podolsky DK (2004) Functional modulation of enterocytes by grampositive and gram-negative microorganisms. Am J Physiol Gastrointest Liver Physiol 286: G613-G626.

25. Vidal K, Grosjean I, evillard JP, Gespach C, Kaiserlian D (1993) Immortalization of mouse intestinal epithelial cells by the SV40-large T gene. Phenotypic and immune characterization of the MODE-K cell line. J Immunol Methods 166: $63-73$.

26. Graham FL, Smiley J, Russell WC, Nairn R (1977) Characteristics of a human cell line transformed by DNA from human adenovirus type 5. J Gen Virol 36: 59-74.

27. Ruiz P, Shkoda A, Kim SC, Sartor RB, Haller D (2005) IL-10 gene deficient mice lack TGFB/Smad signalling and fail to inhibit proinflammatory gene expression in intestinal epithelial cells after the colonisation with colitogenic Enterococcus faecalis. J Immunol 174: 2990-2999.

28. Pfaffl MW (2001) A new mathematical model for relative quantification in realtime RT-PCR. Nucleic Acids Res 29: e45. 
29. Katakura K, Lee J, Rachmilewitz D, Li G, Eckmann L, Raz E (2005) Toll-like receptor 9-induced type I IFN protects mice from experimental colitis. J Clin Invest 115: 695-702.

30. Tilsala-Timisjärvi A, Alatossava T (1997) Development of oligonucleotide primers from the 16S-23s rRNA intergenic sequences for identifying different dairy and probiotic lactic acid bacteria by PCR. International Journal of Food Microbiology 35: 49-56.

31. Ohmori Y, Hamilton TA (1993) Cooperative interaction between interferon (IFN) stimulus response element and kappaB sequence motifs controls IFNy- and lipopolysaccharid-stimulated transcription from the murine IP10 promoter. Journal of Biological Chemistry 268(9): 6677-6688.

32. Kontoyiannis D, Pasparakis M, Pizarro TT, Cominelli F, Kollias G (1999) Impaired on/off regulation of TNF biosynthesis in mice lacking TNF AU-rich elements: implications for joint and gut-associated immunopathologies. Immunity 10: $387-398$.

33. Strober W, Fuss IJ, Blumberg RS (2002) The immunology of mucosal models of inflammation. Annu Rev Immunol 20: 495-549.

34. Yan F, Cao H, Cover TL, Whitehead R, Polk DB (2007) Soluble proteins produced by probiotic bacteria regulate intestinal epithelial cell survival and growth. Gastroenterol. 132: 562-575.

35. Marx N, MAch F, Sauty A, Leung JH, Sarafi MN, Ransohoff RM, Libby P, Plutzky J, Luster AD (2000) Peroxisome proliferator-activated receptor-gamma activators inhibit IFN-gamma-induced expression of the T cell-active CXC chemokines IP-10, Mig, and I-TAC in human endothelial cells. J Immunol 164: 6503-6508.

36. Inatomi O, Andoh A, Kitamura K, Yasui H, Zhang Z, Fujiyama Y (2005) Butyrate blocks interferon-gamma-inducible protein-10 release in human intestinal subepithelial myofibroblasts. J Gastroenterol. 40: 483-489.

37. Tebo J, Kim HS, Gao J, Armstrong DA, Hamilton TA (1998) Interleukin-1 suppresses IP-10 gene transcription by inhibiting the production of class I interferon. Blood 92: 4742-4749.

38. Proost P, Struyf S, Van Damme J (2006) Natural post-translational modifications of chemokines. Biochem Soc Trans. 34: 997-1001.

39. Yu Y, ZEng H, Lyons S, Carlson A, Merlin D, Neish AS, Gewirtz AT (2003) TLR5-mediated activation of p38 MAPK regulates epithelial IL-8 expression via posttranscriptional mechanism. Am J Physio Gastrointest Liver Physiol. 285: G282-290.

40. Van der Steen P, Husson SJ, Proost P, Van Damme J, Opdenakker G (2003) Carboxyterminal cleavage of the chemokines MIG and IP-10 by gelatinase B and neutrophil collagenase. Biochem Biophys Res Commun 310: 889-896.
41. Heo J, Mondal TK, Gao D, Kasten-Jolly J, Kishikawa H, Lawrence DA (2006) Posttranscriptional Inhibition of Interferon-Gamma Production by Lead. Toxicological Sciences 96: 92-100.

42. Shanmugam N, Ransohoff RM, Natarajan R (2006) Interferon-y-inducible protein (IP)-10 mRNA stabilized by RNA-binding proteins in monocytes treated with S100b. Journal of Biological Chemistry 281: 31212-31221.

43. Hensbergen P, Verzijl D, Balog CI, Dijkman R, ven der Schors RC, van der Raaij-Helmer EM, van der Plas MJ, Leurs R, Deelder AM, Smit MJ, Tensen CP (2004) Furin is a chemokine-modifying enzyme: in vitro and in vivo processing of CXCL10 generates a C-terminally truncated chemokine retaining full activity. J Biol Chem 279: 13402-13411.

44. Campanella G, Grimm J, Manice LA, Colvin RA, Medoff BD, Wojtkiewicz GR, Weissleder R, Luster AD (2006) Oligomerization of CXCL10 is necessary for endothelial cell presentation and in vivo activity. J Immunol. 177: 6991-6998.

45. Tien M, Girardin SE, Regnault B, Le Bourhis L, Dillies MA, Coppée JY, Bourdet-Sicard R, Sansonetti PJ, Pédron T (2006) Anti-inflammatory effect of Lactobacillus casei on Shigella-infected human intestinal epithelial cells. J Immunol. 176: 3841.

46. Lahat N, Rahat MA, Kinarty A, Weiss-Cerem L, Pinchevski S, Bittermann H (2008) Hypoxia enhances lysosomal TNF(alpha) degradation in mouse peritoneal makrophages. Am J Physiol Cell Physiol In press.

47. Isowa N, Keshavjee SH, Liu M (2000) Role of microtubules in LPS-induced macrophage inflammatory protein-2 production from rat pneumocytes. Am J Physiol Lung Cell Mol Physiol 279: L1075-1082.

48. Dardalhon V, Géminard C, Reggion H, Vidal M, Sainte-Marie J (2002) Fractionation analysis of the endosomal compartment during rat reticulocyte maturation. Cell Biol Int 26: 669-678.

49. Marinari U, Nitti M, Pronzato MA, Domenicotti C (2003) Role of PKCdependent pathways in HNE-induced cell protein transport and secretion. Mol Aspects Med. 24: 205-211.

50. Schähs P, Weidinger P, Probst OC, Svoboda B, Stadlmann J, Heug H, Waerner T, Mach L (2008) Cellular repressor of E1A-stimulated genes is a bona fide lysosomal protein which undergoes proteolytic maturation during its biosynthesis. Exp Cell Res in press.

51. Chapman T, Plosker GL, Figgitt DP (2006) VSL\#3 probiotic mixture: a review of its use in chronic inflammatory bowel diseases. Drugs 66: 1371-1387.

52. Kim S, Tonkonogy SL, Albright CA, Tsang J, Balish EJ, Braun J, Huycke MM, Sartor RB (2005) Variable phenotypes of enterocolitis in interleukin 10-deficient mice monoassociated with two different commensal bacteria. Gastroenterology 128: 891-906. 